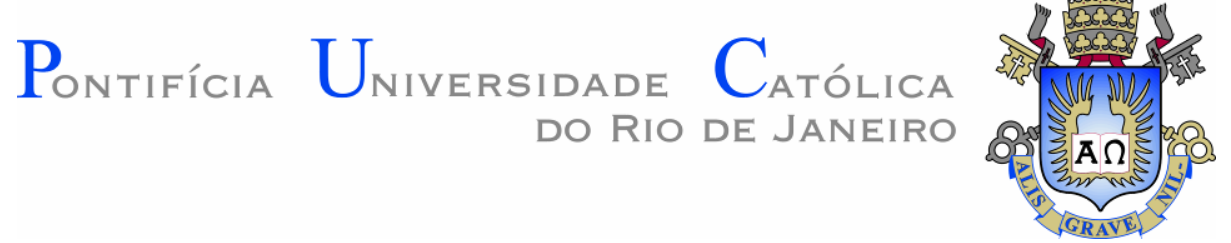

Felipe Malak

\begin{abstract}
A reputação do vendedor dentro do modelo de e-marketplaces B2C e seu impacto na intenção de

compra
\end{abstract}

Dissertação de Mestrado

Dissertação apresentada como requisito parcial para obtenção de grau de Mestre pelo Programa de Pósgraduação em Administração de Empresas da PUCRio.

Orientador: Prof. Jorge Brantes Ferreira

Rio de Janeiro

Fevereiro/2018 


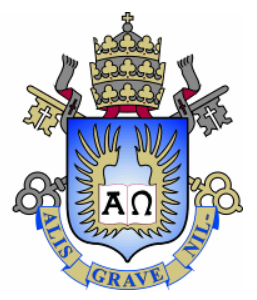

Felipe Malak

\section{A reputação do vendedor dentro do modelo de e-marketplaces B2C e seu impacto na intenção de \\ compra}

Dissertação apresentada como requisito parcial para obtenção do grau de Mestre pelo Programa de Pósgraduação em Administração de Empresas da PUCRio. Aprovada pela Comissão Examinadora abaixo assinada.

Prof. Jorge Brantes Ferreira

Orientador

Departamento de Administração - PUC-Rio

Prof. Marcus Wilcox Hemais Departamento de Administração - PUC-Rio

Prof. Carlos de Lamare Bastian Pinto

Grupo IBMEC

Prof. Augusto Cesar Pinheiro da Silva Coordenador Setorial do Centro de Ciências Sociais - PUC-Rio

Rio de Janeiro, 02 de fevereiro de 2018 
Todos os direitos reservados. É proibida a reprodução total ou parcial do trabalho sem autorização da universidade, do autor e do orientador.

\section{Felipe Malak}

Graduou-se como Administrador na Universidade Federal do Rio de Janeiro (UFRJ) em 2015. Atuou profissionalmente em empresas no setor de telecomunicações e seguros. Atualmente coordena o setor de marketing de uma fábrica de artigos esportivos.

Ficha Catalográfica

Malak, Felipe

A reputação do vendedor dentro do modelo de emarketplaces B2C e seu impacto na intenção de compra / Felipe Malak; orientador: Jorge Brantes Ferreira. - 2018.

72 f. : il. ; $30 \mathrm{~cm}$

Dissertação (mestrado)-Pontifícia Universidade Católica do Rio de Janeiro, Departamento de Administração, 2018.

Inclui bibliografia

1. Administração - Teses. 2. E-commerce. 3. Marketplace online. 4. Comportamento do consumidor. I. Ferreira, Jorge Brantes. II. Pontifícia Universidade Católica do Rio de Janeiro. Departamento de Administração. III. Título. 


\section{Agradecimentos}

Aos meus pais, pelo exemplo de perseverança e dedicação.

Aos meus irmãos, pelo companheirismo e paciência.

A minha namorada Roberta, por todo o incentivo e apoio incontestável.

Aos meus colegas, por toda compreensão, ajuda e companheirismo ao longo do curso.

Ao meu orientador Jorge Brantes, pelo compartilhamento de sua experiência e expertise, tornando o desafio de concluir este trabalho com muita tranquilidade. 


\section{Resumo}

Malak, Felipe; Ferreira, Jorge Brantes. A reputação do vendedor dentro do modelo de e-marketplaces B2C e seu impacto na intenção de compra. Rio de Janeiro, 2018. 72p. Departamento de Administração, Pontifícia Universidade Católica do Rio de Janeiro.

A vez das plataformas de marketplace online finalmente chegou no Brasil, um modelo de negócio que conecta compradores com vendedores por meio de um intermediário. A aplicação desse tipo de comércio em larga escala trouxe consigo diversas modificações no relacionamento entre empresas e consumidores dentro de um ambiente online já bastante carregado de incertezas acerca do objeto de compra. No entanto, grandes empresas que exercem o papel de intermediadoras nessas plataformas, passam a priorizar o volume de acessos de usuários em seus domínios acima das demais atividades relacionadas ao processo de compra em si. O crescente número de reclamações e processos visando reparação de danos de consumidores indica uma piora no setor em geral. Nesse sentido, essa pesquisa busca investigar a importância relativa das percepções do comprador sobre as reputações dos vendedores terceiros, e, seus efeitos na relação de risco percebido e confiança das empresas envolvidas no modelo de marketplace e os consequentes impactos na intenção de compra dos consumidores online. Uma survey online foi conduzida com indivíduos brasileiros que compraram em lojas virtuais ao longo dos últimos 12 meses. Os dados obtidos confirmam as hipóteses colocadas, sugerindo que avaliações de reputações de vendedores exercem influência na intenção de compra por meio de percepções de confiança e risco percebido no processo de compra. Algumas sugestões são propostas para que empresas do setor de e-commerce otimizem seus esforços dentro e fora de ambientes de marketplaces online.

\section{Palavras-chave}

E-commerce; marketplace online; comportamento do consumidor. 


\section{Abstract}

Malak, Felipe; Ferreira, Jorge Brantes (Advisor). The seller's reputation on e-marketplace B2C model and purchase intention impacts. Rio de Janeiro, 2018. 72p. Departamento de Administração, Pontifícia Universidade Católica do Rio de Janeiro.

Online marketplace platforms finally arrived in Brazil, a business model that connects buyers with sellers through an intermediary party. This particularly application of commerce in large scale has brought with it several modifications in the relationship between companies and consumers, taking in account an online environment already quite loaded with uncertainties on buy process. However, large companies that act as intermediaries in these platforms, prioritize the volume of user accesses in their domains above the other activities related to the purchase process itself. The growing number of complaints and lawsuits seeking compensation for consumer losses indicates a decline in the industry as a whole. Considering that, this research seeks to investigate the relative importance of buyer perceptions on the reputations of third-party vendors and their effects on the perceived risk and trust relationship of the companies involved in the marketplace model and the consequent impacts on consumers' online purchase intention. An online survey was conducted with Brazilian individuals who shopped at virtual stores over the last 12 months. The research's data confirmed all the hypotheses formulated, suggesting that evaluations of reputations of seller's influence in the intention to buy through perceptions of confidence and perceived risk. Some suggestions are proposed for companies in the e-commerce industry to optimize their efforts inside and outside marketplaces online.

\section{Keywords}

E-commerce; e-marketplace; consumer behavior. 


\section{Sumário}

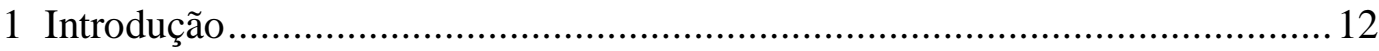

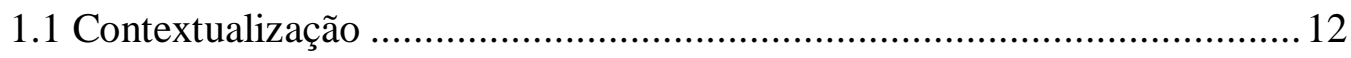

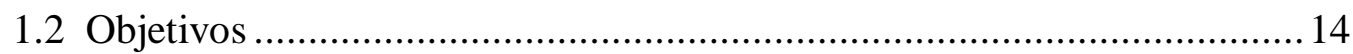

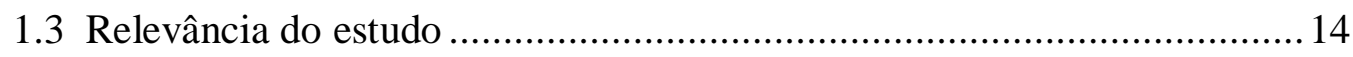

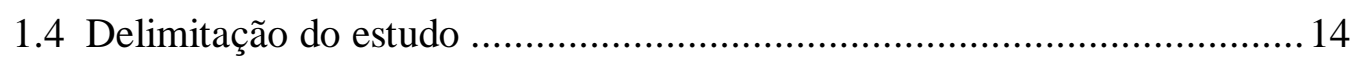

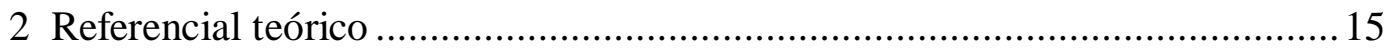

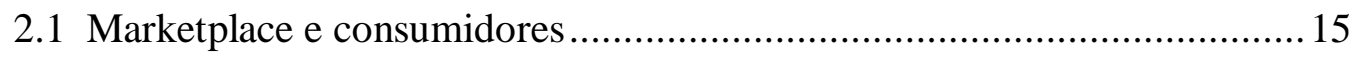

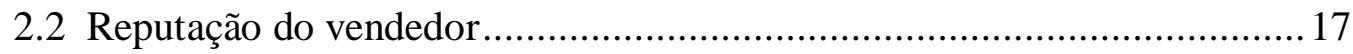

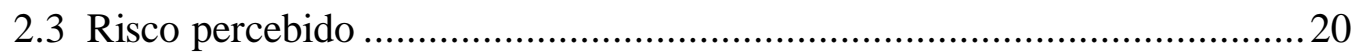

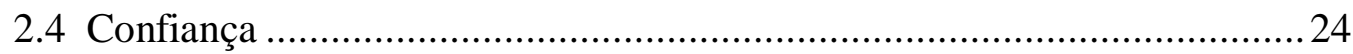

2.4.1 Confiança no intermediário ......................................................... 26

2.4.2 Confiança no vendedor............................................................... 27

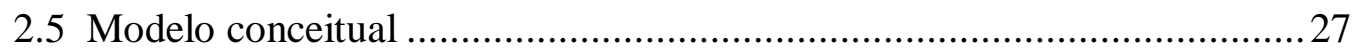

2.5.1 A reputação da loja terceira e a percepção de risco .......................... 27

2.5.2 A reputação das lojas terceiras com a confiança no intermediário

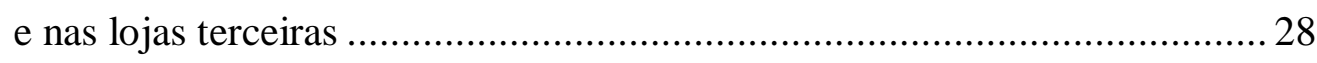

2.5.3 A percepção de risco com a confiança no intermediário e na loja

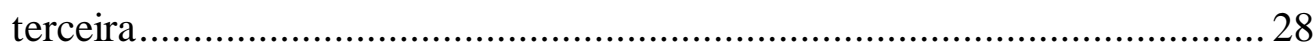

2.5.4 Confiança no intermediário com confiança no vendedor terceiro ....... 29

2.5.5 A confiança e a intenção de compra................................................ 29

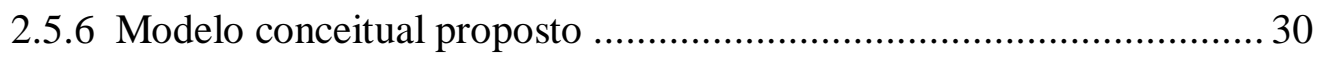

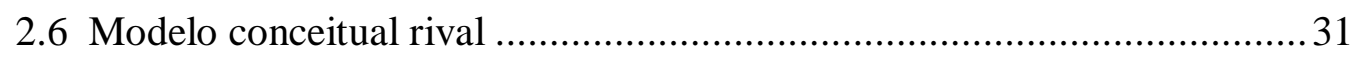

2.6.1 A confiança e o risco percebido ..................................................... 31

2.6.2 O risco percebido e a intenção de compra ........................................ 32

2.6.3 Modelo conceitual rival proposto ............................................... 32

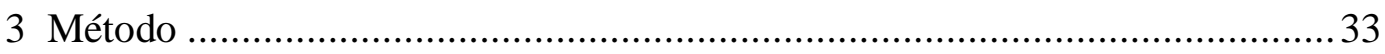

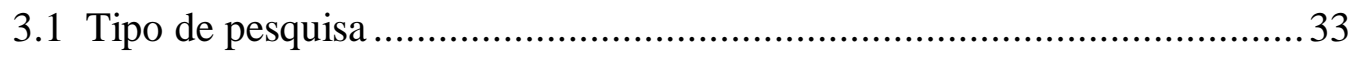

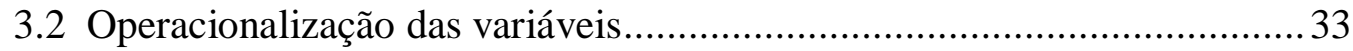

3.2.1 Definição Operacional das variáveis .................................................. 34

3.2.2 Procedimentos de tradução e Adaptação das escalas utilizadas .......... 34

3.2.3 Pré-teste do instrumento de pesquisa ............................................ 34

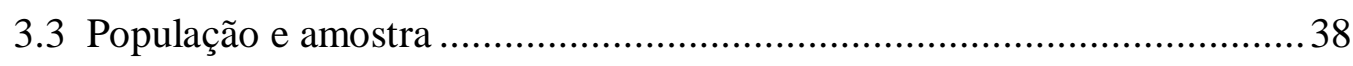




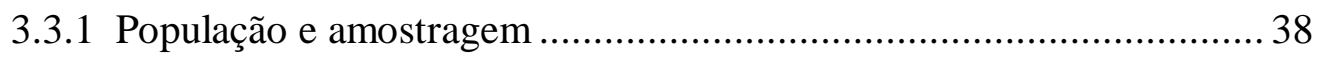

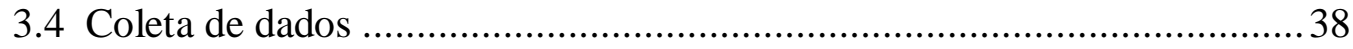

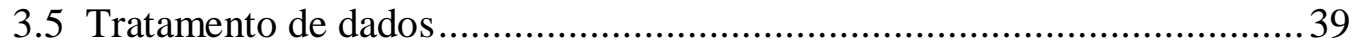

3.6 Análise estatística ................................................................................... 40

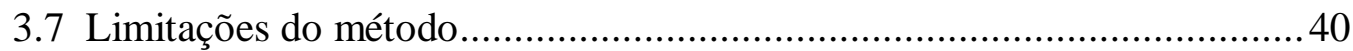

3.7.1 Relacionadas ao critério da amostragem ............................................. 41

3.7.2 Relacionadas à coleta de dados ......................................................... 41

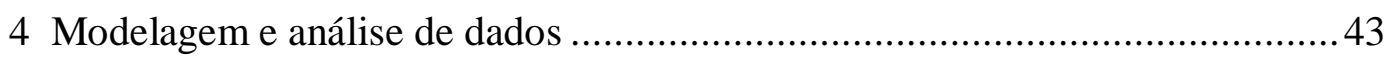

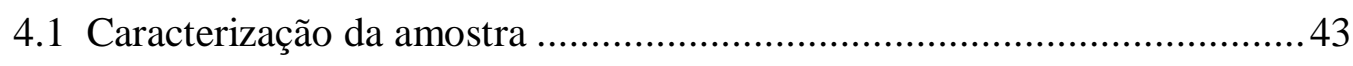

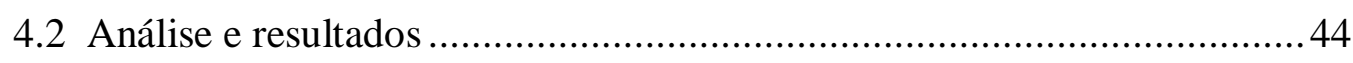

4.2.1 Análise do modelo de mensuração ...................................................... 44

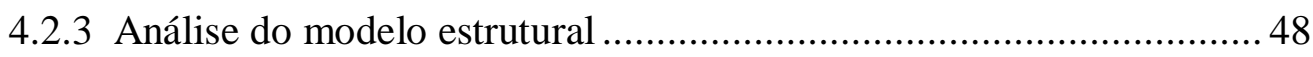

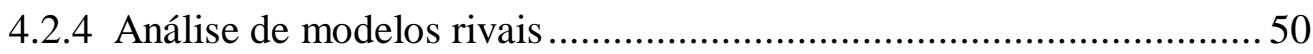

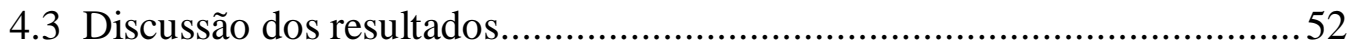

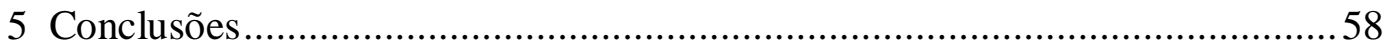

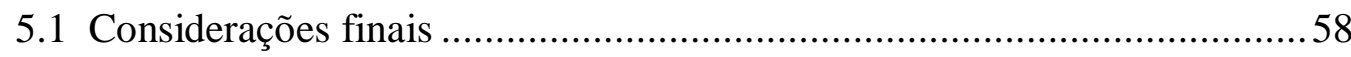

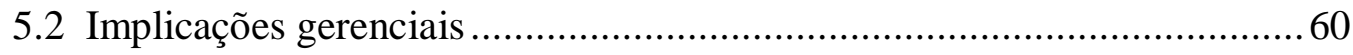

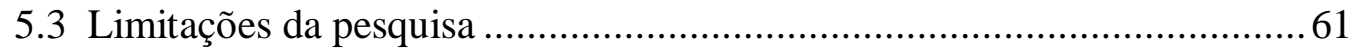

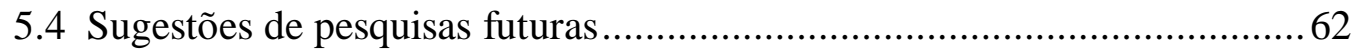

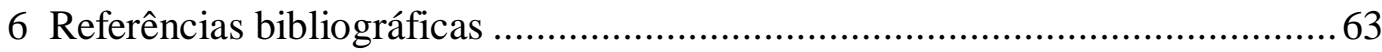

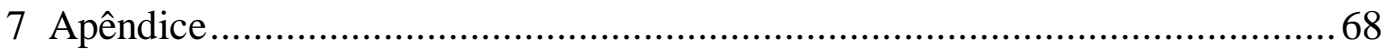




\section{Lista de Figuras}

Figura 1: Modelo conceitual proposto ......................................................... 31

Figura 2: Modelo conceitual alternativo proposto ............................................ 32

Figura 3: Coeficientes Padronizados Estimados,

Hipóteses e Significâncias para o Modelo Proposto............................................. 50

Figura 4: Coeficientes Padronizados Estimados,

Hipóteses e Significâncias para o Modelo Rival Proposto ................................. 52 


\section{Lista de tabelas}

Tabela 1: Características da Amostra............................................................. 44

Tabela 2: Análise de Confiabilidade, Confiabilidade Composta e

Variância Média Extraída................................................................................... 47

Tabela 3: Índices de Ajuste do Modelo.......................................................... 48

Tabela 4: Coeficientes Padronizados Estimados,

Hipóteses e Significâncias para o Modelo Proposto............................................. 49

Tabela 5: Índices de Ajuste do Modelo........................................................... 51

Tabela 6: Coeficientes Padronizados Estimados,

Hipóteses e Significâncias para o Modelo Rival Proposto ................................. 51

Tabela 7: Comparativo de Índices e resultados entre modelos ........................... 56

Tabela 8: Coeficientes padronizados estimados e

significâncias para os modelos estruturais proposto e rival ................................56 


\section{Lista de Quadros}

Quadro 1: Definição operacional das variáveis .............................................. 36

Quadro 2: Matriz de Correlação entre Construtos ............................................. 46

Quadro 3: Matriz de Validade Discriminante .................................................. 47 


\section{1 \\ Introdução}

\section{1}

\section{Contextualização}

O faturamento e volume de transações oriundas de e-commerce crescem ano após ano no Brasil (B2W, 2017) e no mundo (OLIVEIRA et al., 2017). Nos relatórios de demonstração de resultados da B2W e outras empresas do setor são exaltados o crescente volume de transações, e, em particular, o rápido avanço dentro do modelo de negócio de agenciamento (B2W, 2017; E-COMMERCEBRASIL, 2017a), no qual vendedores terceiros ofertam produtos e/ou serviços dentro de uma plataforma de integração fornecida por um site de compras, geralmente de maior volume de acessos (HONG; CHO, 2011). Diversos autores (HONG; CHO, 2011; WU et al., 2015; YOO; JEON; HAN, 2016) referem-se a este modelo de negócio como e-marketplaces.

Dentre os possíveis motivos para grandes empresas de e-commerce adotarem estratégias de negócios por e-marketplaces estão: o aumento da capacidade de vendas; a redução de custos e perdas de estoque; aceleração do fluxo de caixa; aumento do alcance de entrega; redução de tempo logístico (B2W, 2017)

O consumo online diferencia-se das demais transações comerciais pelas características marcadas pela distância e falta de contato interpessoal entre comprador e vendedor (PAVLOU, 2003). Quando compram online, consumidores avaliam ofertas sob incerteza acerca da transação (PAVLOU, 2003; ZHANG et al., 2017). A incorporação de novas tecnologias na navegação de sites de compras pode impactar ainda mais a percepção dos usuários em relação à sua facilidade de uso e consequente intenção de compra (WU et al., 2015). Comparando a canais de varejo offlines, os consumidores ficam expostos a uma quantidade maior de informações e propagandas, podendo prejudicar tanto o prazer de navegação, quanto aumentar o custo cognitivo por conta do incremento de avaliações necessárias (YAN et al., 2016).

Em se tratando de e-marketplaces, os desafios de tornar a experiência do usuário mais prazerosa começam a partir: da listagem dos produtos (COLUCCI et al., 2006), exibição de preços (WU et al., 2015), contraste de poluição visual (WU et al., 2016) e classificação de comentários (YOO; JEON; HAN, 2016). Hong e Cho (2011) ressaltam a vulnerabilidade deste modelo de negócio para a ocorrência de fraudes, uma vez que as lojas intermediárias não se responsabilizam pelo controle do envio das compras efetuadas. Não obstante, o grande volume 
de vendedores terceiros dentro de lojas intermediárias mostra-se como um grande desafio, tanto na operação logística e de sistema de gerenciamento (CHANG; CHEN, 2008), quanto também, no atendimento pós-vendas (JOLIVET; JULLIEN; POSTEL-VINAY, 2015).

Tendo em vista as possibilidades de frustração com compras virtuais, sites especializados em avaliações e reclamações de consumidores (reclameaqui.com.br; ebit.com.br) oferecem ferramentas de auxílio e alertas sobre lojas de comércio eletrônico não recomendadas. Recentes reportagens (E-COMMERCEBRASIL, 2017b; PROCON-SP, 2017) colocam empresas tradicionais do varejo brasileiro liderando rankings de reclamações antes dominados por outros setores empresariais no Brasil, segundo o PROCON-SP (2017), 89\% das reclamações são oriundas da plataforma de e-commerce da empresa.

Dentro desse contexto, diversas ferramentas de cunho tecnológico são desenvolvidas dentro do ambiente de consumo online. Lu, Fan e Zhou (2016) enfatizam a quebra do paradigma de orientação dos e-commerces, uma vez foram centrados na venda de produtos ao passo de que atualmente se buscam formas de melhorar a experiência do usuário, protagonista e elemento principal no desenvolvimento de interações dentro da internet, criando comunidades virtuais. Surge nesse cenário o sistema de avaliações, que se torna um componente chave dentro de um site de vendas, que fornece aos usuários a possibilidade de expor suas opiniões, acerca de produtos e vendedores, servindo de base para decisões de outros consumidores (ZHANG et al., 2017).

Num estudo sobre um marketplaces online chinês, Wang et al. (2016) indicam que, mesmo sendo fisicamente iguais, alguns produtos podem ser percebidos das mais diferentes maneiras através de seus anúncios ou pela reputação dos vendedores. Lu et al., (2016) confirmam que o papel dos marketplaces não se limitam apenas a servirem como um intermédio entre compradores e vendedores, mas como provedores de soluções para as partes interessadas.

A partir daí a introdução de novos agentes nas relações comerciais, e, consequentemente na inclusão de uma nova variável na percepção de risco destas transações, torna-se necessário verificarmos a percepção dos consumidores sobre a reputação dos vendedores e suas consequências. Observando esses fatores, que efeitos são percebidos na intenção de compra no e-marketplace levando em consideração a confiança colocada, tanto na loja intermediária quanto nas lojas terceiras, diante das avaliações dos consumidores sobre a reputação dos vendedores terceiros? 


\section{2 \\ Objetivos}

Este estudo pretende investigar a importância relativa das percepções do comprador sobre as reputações dos vendedores terceiros de e-marketplaces $\mathrm{B} 2 \mathrm{C}$, e, seus efeitos na relação de risco percebido e confiança das empresas envolvidas no modelo comercial e os consequentes impactos na intenção de compra dos e-consumidores.

\section{3}

\section{Relevância do estudo}

Este estudo espera contribuir para a literatura acadêmica com a introdução da avaliação da reputação de vendedores terceiros com o propósito de análise da construção de confiança e intenção de compra em modelos de marketplace online. O escopo de pesquisa mostra-se inédito por avaliar a percepção dos consumidores em relação à reputação de vendedores terceiros. Em outros estudos foram abordados apenas conceitos que envolveram a dispersão de preços (WU et al., 2015) e imagens de produtos(WU et al., 2016). O entendimento do comportamento dos efeitos desta ferramenta é relevante na medida em que se observa o crescente número de empresas dedicadas a tal atividade (GEFEN; PAVLOU, 2012).

Pelo ponto de vista gerencial, a perturbação do comportamento de compra dos consumidores tem como consequência direta, impactos sobre os retornos de investimentos tanto das lojas integradoras quanto para os vendedores terciários e lojas de e-commerce em geral. Uma vez que o mercado está em processo de desenvolvimento e maturação, com continua dependência de incremento e sustentação de confiança. (OLIVEIRA et al., 2017).

\section{4}

\section{Delimitação do estudo}

Esta pesquisa estabelece como cerne as avaliações dos consumidores online sobre a reputação dos vendedores terceiros dentro dos e-marketplaces B2C. A escolha de mercados B2C se deve ao fato do volume de transações comerciais observadas em território nacional (WEBSHOPPERS, 2017) e níveis mais altos de profissionalização dos ofertantes (HONG, 2015). Em particular, foi escolhida a plataforma de e-marketplace da loja online Americanas.com pelo fato de atender à condição de comércio exclusivamente $\mathrm{B} 2 \mathrm{C}$ e possuir o maior volume de acessos de usuários nos últimos seis meses (Similarweb, 2017), proporcionando um exemplo prático aos respondentes da pesquisa. 


\section{2 \\ Referencial teórico}

Neste capítulo são apresentados os conceitos chave utilizados como referencial teórico deste estudo. São apresentados a seguir, fatores relevantes que impactam na intenção de compra dentro do ambiente virtual. Para esta pesquisa, foram consultados diversos artigos científicos de periódicos internacionais, especialmente aqueles que remetiam a comércio eletrônico, sistemas de informação e comportamento dos consumidores em ambientes virtuais. Neste trabalho, os construtos estudados serão conduzidos de maneira semelhante à literatura do campo de estudo de comércio eletrônico, no qual existe um consenso geral em torno de que confiança e risco são não só são determinantes ao comportamento de consumo (CHANG; CHEN, 2008; PAVLOU; GEFEN, 2004; WU et al., 2015), mas os mais relevantes na dinâmica de compras online (GEFEN; PAVLOU, 2012).

\section{1 Marketplace e consumidores}

Desde o surgimento dos sites de leilão virtual eBay.com e da ascensão na internet da amazon.com, seus modelos de negócios e consequências para os consumidores são discutidas na literatura acadêmica (JARVENPAA; TRACTINSKY; SAARINEN, 1999; PAVLOU, 2003). Mais recentemente, o fenômeno das plataformas chinesas do grupo Alibaba vêm ganhando cada vez mais destaque na academia. Em comum, essas empresas adotam estratégias de vendas nas quais, vendedores terceiros ofertam produtos e/ou serviços dentro de uma plataforma de integração fornecida por um site de compras, geralmente com maior volume de acessos (HONG; CHO, 2011). Diversos autores (HONG; CHO, 2011; WU et al., 2015; YOO; JEON; HAN, 2016) definem este modelo de negócio como e-marketplaces ou marketplaces online.

Com certas peculiaridades envolvidas neste modelo de negócio, marketplaces online são tratados de maneira diferente na literatura. Ao contrário de sites de comércio eletrônico que comercializam apenas os produtos que possuem em seus estoques, e-marketplaces oferecem produtos e serviços de vendedores a priori desconhecidos dos consumidores (KIM; AHN, 2006). 
Outros autores ressaltam uma certa característica observada entre os vendedores terceiros. Muitos dos vendedores terceiros consistem em pequenos comerciantes tipo $\mathrm{SOHO}$ (small office home office), limitando a capacidade de lidar com altos volumes transacionais e altos níveis de serviço se comparados a grandes corporações com diversos recursos à disposição (HONG, 2015). Não obstante, este tipo de modelo de negócio pode causar os mais diversos tipos de transtornos aos consumidores. Como as transações envolvem não só o intermediário como também o vendedor em si, em muitas situações não é claramente observável a responsabilidade da tomada de ação caso algum problema aconteça, seja no meio do processo de compra, ou, no pós-venda (HONG; CHO, 2011).

Assim como em lojas virtuais do tipo convencionais, marketplaces online são lojas nas quais os compradores fazem o pagamento antes de receberem o produto ou serviço. $\mathrm{O}$ consumidor obtém ao final do processo de compra a promessa de entrega do que foi adquirido (EKMEKCI, 2011).

Dentro do universo de e-marketplaces existem algumas variações acerca de sua natureza. Alguns autores diferenciam a essência dos sites entre apenas plataformas e sites que atuam não só como marketplaces online mas também revendem mercadorias (JOLIVET; JULLIEN; POSTEL-VINAY, 2015). Entre aqueles que podem ser chamados de plataformas puras, podemos observar alguns exemplos como o iFood (serviço de delivery de refeições), Booking (reserva de hotéis), Uber (serviços de transporte), Workana (serviços intelectuais especializados) e MercadoLivre (venda e troca de produtos). Os sites compostos pelo grupo B2W, por exemplo, são podem ser caracterizados dentro do conceito de plataforma mista, já que também atuam como revendedores e possuem estoque de mercadorias destinados à comercialização (B2W, 2017).

De acordo com Lu et al., (2016), o papel das lojas intermediárias é estabelecido por meio de ferramentas que não terminam no desenvolvimento de softwares e a gestão de informação, mas por todo aparato institucional que inclui a disponibilidade de busca e fornecimento de informações, classificação de produtos e ofertantes, comentários reais de compradores, canal de intercomunicação entre consumidores e comerciantes, e também, se posicionam como instituições que garantem a fluidez de pagamentos entre as partes envolvidas nas transações comerciais. Quando bem empregados, todos esses mecanismos têm o objetivo de contribuir para um melhor ambiente para negócios, inibindo comportamentos oportunistas com penalidades e encorajando ações mais justas (LU et al., 2016).

No entanto, nem sempre os marketplaces onlines seguem à risca todas as orientações para promover um bom ambiente de negócios. Segundo Ekmekci, (2011), em busca de solução 
para seus problemas, os compradores podem recorrer a tribunais e mecanismos legais para reaver seus direitos. Os custos de processos na justiça são caros, tanto para compradores quanto para vendedores, o que pode inibir ações oportunistas em situações de falta de informação no decorrer do processo de compra (EKMEKCI, 2011).

Nesse mesmo sentido, Fang et al. (2014) buscam entender os efeitos moderadores entre a confiança e os consumidores nas lojas online. Os resultados mostram que a percepção de eficácia dos mecanismos institucionais nas lojas de comércio virtual oferece maiores retornos para a construção de confiança da loja online, dentre elas, a reputação do vendedor se apresenta como a mais significante. Isso é, o processo de decisão de quem comprar volta a se tornar relevante e merecedor de investigação (HONG, 2015).

\section{2 \\ Reputação do vendedor}

Em ambientes de compra online, todo tipo de informação que está à disposição do consumidor para avaliação é levado em consideração no processo de compra sendo entendida como um fator benéfico e de alto sucesso para os negócios. Segundo pesquisas recentes (WU et al., 2015; YOO; JEON; HAN, 2016), o conteúdo informacional direcionado ao consumidor tem por objetivo aliviar as incertezas em torno das decisões de compra e reduzir a assimetria de informação entre comprador e vendedor.

Nos últimos anos, foi observado (WIGAND; BENJAMIN; BIRKLAND, 2008) o fenômeno de empoderamento dos usuários na rede. A nova cara da internet remete a um grande local de encontros entre pessoas, que não deixou os sites de compra de lado. O social commerce promove o uso das lojas virtuais por meio da participação ativa dos consumidores através da disponibilidade de ferramentas comparativas, opinativas, de busca por produtos e avaliação de suas experiências, tudo isso em ofertas e sites cada vez mais personalizados e interativos. Essa mudança representa uma mudança de paradigma que a comunicação não se dá apenas em via de mão única, mas dentro de um ambiente inter-relacionado com os usuários sendo peças chave no design dos sites e mecanismos de interação (HUANG; BENYOUCEF, 2013; WIGAND; BENJAMIN; BIRKLAND, 2008; ZHOU; ZHANG; ZIMMERMANN, 2013).

Nesse sentido, enquanto a maioria dos esforços de comunicação são conduzidas pelos ofertantes como uma ferramenta para alavancar vendas, sistemas de avaliação tendem a produzir informações mais convincentes para os usuários, na medida em que a origem do comunicador é imparcial (SHAN, 2016). Grande parte dos sites de comércio virtual 
estabelecem mecanismos de avaliação de vendedores e compartilham as informações (de modo analítico ou sintético) aos usuários que trafegam no site (WANG et al., 2016), porque as pessoas tendem a acreditar em informações que encontram na internet muitas vezes em prol de fontes de informação mais tradicionais (FLANAGIN et al., 2014).

Ekmekci (2011) reforça que a reputação armazenada em sites de compras soma aos mecanismos de busca como um fator chave no processo de decisão dos consumidores, armazenando um histórico de experiências um único repositório. Segundo Jolivet, Jullien e Postel-Vinay (2015), um dos maiores desafios no desenvolvimento e planejamento de lojas do tipo marketplace é estabelecer um ambiente que seja competente no combate a fraudes e comportamentos inadequados dos vendedores terceiros. Nesse sentido, os autores verificaram que boas reputações são acompanhadas de transações em preços médios mais altos, um prêmio adquirido por meio de seu reconhecimento.

O produto desses sistemas de avaliação e reputação oferece uma nova fonte de informações que ajudam compradores a prospectar o comportamento dos vendedores nas lojas virtuais (WU; HUANG; FU, 2011). Pelo lado das lojas intermediárias e dos vendedores presentes nas plataformas de marketplace online, esses sistemas implicam em um novo método disponível para alavancar a credibilidade no site promovendo a avaliação de produtos e serviços (FLANAGIN et al., 2014).

No entanto, visto que sistemas de avaliação de vendedores tem sua relevância, outros estudos colocam a marca do site como o principal ativo da empresa, até acima da questão da qualidade de interface e ferramentas à disposição dos usuários (CHANG; CHEN, 2008). Esse pequeno conflito se mostra um contraditório em plataforma do tipo e-marketplace, já que esses necessitam de diversos mecanismos de comparação e exibição de informações, porém, sugere que lojas intermediárias se protejam muito bem de eventuais comportamentos indesejados dentro do serviço que elas propõem.

Em contrapartida, outros trabalhos buscaram analisar em específico a dinâmica entre sistemas de reputação e seus reflexos no desempenho das empresas que se estabeleceram em atuação de vendas dentro de plataformas de marketplace online. Ao observarem firmas já estabelecidas na plataforma, (FAN; JU; XIAO, 2016) indicam que sistemas de reputação favorecem o desempenho, mas, de maneira distinta entre as empresas, onde novos entrantes sofrem com a falta de histórico e que estratégias de redução de preços são altamente arriscadas para a sobrevivência do negócio. Os preços mais baixos para atrair consumidores não proporcionam lucros para a sustentabilidade da operação, ou, sobrecarregam a capacidade da empresa ocasionando serviços prestados inadequados. 
Sendo assim, os efeitos das reputações dos vendedores terceiros em ambientes de marketplaces online merecem ser avaliados por meio da percepção dos usuários e consequências nos seus processos de compra. Desta forma, a reputação dos vendedores pode ser entendida como a formação de uma crença a respeito das qualidades e potenciais benefícios oferecidos (SHAPIRO, 1982). Em estudos recentes, a reputação dos vendedores é utilizada como um meio de alinhamento de expectativas entre o ofertante e os potenciais consumidores (WALSH et al., 2016).

Como Wang et al. (2016) detalham, a percepção sobre a qualidade de determinado bem é constituída por meio do envolvimento que o consumidor tem com o produto em conjunto com a reputação disponível que o consumidor forma sobre o vendedor, minimizando o efeito possíveis problemas com vendedores, desde o atraso na entrega da mercadoria, imperfeições sobre a apresentação do produto na página de compra ou qualquer outro problema que gere algum transtorno na aquisição (JOLIVET; JULLIEN; POSTEL-VINAY, 2015). Apesar de pesquisas (SHAN, 2016; WU et al., 2016) apontarem que consumidores enxergam certo ceticismo a respeito da veracidade das avaliações em determinados sites de compra que não promovem segurança de imparcialidade de informações para os usuários.

Contudo, a força da reputação do vendedor sobre a avaliação dos consumidores depende de como ela é formada (CAI et al., 2014). Shan (2016), por exemplo, destaca as possíveis variações na percepção das avaliações em virtude da percepção de expertise do usuário que avaliou. Por outro lado, Wang et al., (2016) enfatizam que em situações de procura de produtos de baixo envolvimento, a reputação dos vendedores é mais significativa na percepção de qualidade da oferta do que a apresentação dos produtos em si.

Assim como as percepções variam, as consequências de um acumulo de avaliações ruins também pode oscilar. Por um lado, foi observado que na medida em que um vendedor só recebe boas avaliações, a partir do primeiro parecer ruim, o comerciante já pode verificar quedas substanciais nas vendas (CABRAL; HORTAÇSU, 2010). Por outro lado, Fan, Ju e Xiao (2016), não compartilham do efeito imediato nas vendas para empresas com vasto histórico.

Em seu estudo estratégico, Ekmekci (2011) mostra como reputações podem ser sustentadas ao longo do tempo se, as avaliações passadas são mostardas e reguladas por mecanismos centrais explícitos. Em suma, as transações comerciais em lojas virtuais dependem não apenas da adoção por parte dos consumidores ao canal e suas tecnologias, mas principalmente pelo reconhecimento de que os revendedores são comerciantes confiáveis (PAVLOU, 2003). 
As formas como as informações disponíveis aos potenciais consumidores também é outro fator variável na análise de um sistema de e-marketplace, muito por conta das peculiaridades de cada plataforma tecnológica e estratégia empresarial das lojas intermediárias. O produto desta variedade de tipologias de avaliações e relações comerciais traz a cada pesquisa um objeto de análise diferente. Por um lado, observam-se estudos em plataformas do tipo C2C com sistemas de avaliação mútua (vendedores avaliam clientes e vice-versa) e toda a dinâmica de possíveis retaliações ocasionadas por atendimento mal prestados (BOLTON; GREINER; OCKENFELS, 2013; CAI et al., 2014; EKMEKCI, 2011). Nesse sentido, destacam-se plataformas de avaliações do tipo doubleblind review (mercadolivre.com; ebay/china) inibindo comportamentos condicionados pré-estabelecidos e assegurando opiniões mais verdadeiras (BOLTON; GREINER; OCKENFELS, 2013). Por outro lado, marketplaces online que centralizam avaliações oriundas de mão única, se esforçam para promover a exibição da quantidade de avaliações realizadas junto a um resultado agregado para melhor julgamento do usuários (FLANAGIN et al., 2014; JOLIVET; JULLIEN; POSTEL-VINAY, 2015). Mesmo assim, as lojas intermediárias podem decidir exibir os mais variados tipos de escalas de pontuação dos vendedores (FAN; JU; XIAO, 2016), desde uma ordenação por quantidade de estrelas e cores variadas até simples escalas de notas gerais (começando em 0 até 5 , ou, de 0 até 10). Contudo, ambas abordagens concordam em relação à importância da manutenção e exibição das avaliações de consumidores passados em um sistema centralizado, que promove tanto a busca pela manutenção de reputações bem consolidadas quanto no incentivo de desenvolvimento de resultados ruins ou medianos (CAI et al., 2014; EKMEKCI, 2011).

Portanto, as avaliações de consumidores passados se tornam parte da identidade dos vendedores (EKMEKCI, 2011), permitindo potenciais consumidores analisar performances e alinhar expectativas em relação à oferta de serviços. As lojas intermediárias se comportam como responsáveis não só pela seleção dos ofertantes (e que nível de profissionalização exercem), mas também, por todo o serviço de conciliação, treinamento e orientações aos comerciantes presentes em suas plataformas (JOLIVET; JULLIEN; POSTEL-VINAY, 2015). Por fim, reputações são fundamentais, compradores reagem a informação disponível sobre as opiniões em relação aos vendedores (CABRAL; HORTAÇSU, 2010).

\section{3}

\section{Risco percebido}


$\mathrm{O}$ risco percebido tem sido discutido há décadas, muito antes da disseminação do consumo online. Como formalmente definido por Bauer (1960), o risco percebido é formado pela combinação de incerteza e consequências envolvidas da decisão do processo de compra. Algumas pesquisas ainda apontam que o risco percebido atua como força majoritária no comportamento tendo em vista que os consumidores são mais motivados a evitar contratempos do que maximizar utilidade na decisão de compra (MITCHELL, 1999). Da mesma forma, quando consumidores avaliam produtos e marcas, Peter e Ryan (1976) sugerem que aqueles que são altamente avessos a riscos buscam medir potenciais perdas em suas escolhas.

Segundo Wu et al. (2015), o risco como uma possível ameaça, se torna uma influência negativa dentro do processo de compra dos consumidores, prejudicando a avaliação do valor percebido de sua aquisição. Os autores desenvolvem a afirmação sob o raciocínio de que os riscos indicam potenciais custos que estão localizados no futuro, contudo, consumidores virtuais avaliam mediante seus comportamentos no presente, isso é, a partir dos custos envolvidos no momento da compra na loja online.

Dentro de e-marketplaces, Kim e Ahn, (2006) destacam a ação da comunidade de vendedores desconhecidos na formação de barreiras de riscos para possíveis consumidores. Verhagen, Meents e Tan (2006) sugerem que dentro de uma plataforma de marketplace online, por exemplo, compradores necessitam enfrentar riscos tanto em relação ao ofertante de fato quanto ao intermediário do sistema.

Chiu et al. (2014) sugerem que as percepções dos consumidores acerca do risco percebido precisam ser minimizadas para que, dentro de um nível aceitável, os compradores possam combinar os níveis de riscos que estão dispostos a aceitar dentro daqueles determinados benefícios que esperam receber naquela transação. Gefen e Pavlou (2012) também admitem que a percepção dos consumidores na eficácia das estruturas institucionais agem como moderadores na percepção de risco em transações comerciais na internet, diminuindo as incertezas dos consumidores.

As origens das incertezas em transações comerciais podem ser tanto de natureza no ambiente das compras online, quanto geradas em virtude de comportamentos não desejados dos vendedores (PAVLOU, 2003). Dentro da natureza do ambiente virtual, pesquisas (PAVLOU, 2003; PAVLOU; GEFEN, 2004, 2005) destacam dimensões específicas para transações online, entre elas: a falta de intimidade em utilizar ferramentas tecnológicas; a impessoalidade da negociação comercial; e a incerteza perante a funcionalidade correta das instituições intermediadoras comerciais. 
Deste modo, a natureza impessoal do ambiente de compra online traz consigo inseguranças a respeito das expectativas formuladas no processo de compra (PAVLOU, 2003). O risco em relação ao ambiente torna-se um elemento indissociável do e-commerce face aos possíveis ataques de hackers em roubos de informações pessoais e cartões de crédito dos usuários (PAVLOU, 2003). Portanto, a efetividade das instituições na proteção dos interesses dos consumidores, atuam como estruturas que garantem a segurança dentro do ambiente online (PAVLOU; GEFEN, 2005). Como Gefen e Pavlou (2012) colocam, a percepção do funcionamento das instituições se torna um importante mediador de vulnerabilidade dos consumidores em meio de uma plataforma de e-marketplace.

Em segundo lugar, pesquisas ressaltam que consumidores virtuais se deparam com incertezas a respeito do comportamento daquelas empresas e pessoas envolvidas nas transações comerciais na internet. Quando usuários de lojas virtuais navegam em ambientes que não transmitem previsibilidade acerca dos serviços prestados, o comportamento posterior dos consumidores é afetado por sua capacidade limitada de raciocínio das possíveis variáveis que intermediariam a sua compra, bem como a percepção de possíveis comportamentos oportunistas daqueles que propõe os serviços da loja virtual (GEFEN; CARMEL, 2013; WILLIAMSON, 1979).

Dentre os exemplos possíveis de comportamento oportunístico de vendedores online são observados desencontros sobre informações do anúncio, vazamento de informações particulares dos consumidores, falsidade ideológica, propaganda enganosa e descumprimento de garantia (PAVLOU, 2003). Levando em consideração uma das características mais acentuadas em pesquisas sobre consumo online, a distância e falta de contato do comprador com a mercadoria, estudos mostram que o ambiente virtual é propicio para comportamentos fraudulentos (HONG, 2015), em que a carência de experimentação conduz a decisões baseadas em informações projetadas pelos ofertantes, uma oportunidade para condutas antiéticas se compradas em relação a ambientes off-line (RIQUELME; ROMÁN; IACOBUCCI, 2016). No mesmo sentido, Wu et al. (2016) exemplificam que imagens são alvos de manipulação por vendedores em ações intencionais para enganar o consumidor, visto que usuários costumam prestar muito mais atenção em fotografias para entender e visualizar o que estão comprando.

Não obstante, Hong (2015) procura entender como consumidores selecionam os comerciantes de acordo com seus maiores interesses, levando em consideração o nível de envolvimento com o produto e o risco percebido. Contudo, Wu et al. (2015) destacam nesse aspecto que produtos de alto valor agregado oferecem grandes oportunidades para comportamentos de má fé, nos quais vendedores terceiros de e-marketplaces aplicam preços 
incondizentes com o intuito de atrair consumidores ingênuos. Isso ocorre muito por conta da variação do nível de assimetria de informação entre compradores e vendedores (BA; PAVLOU, 2002).

Por consequência, as compras online disseminam riscos associados em reflexo das incertezas acerca dos serviços prestados após a compra, podendo ser originados de erros das empresas envolvidas no processo de compra, ou por conta de condutas previamente articuladas para trapacear o comprador. Wu et al. (2015) destacam que em mercados de e-marketplace, consumidores podem se sentir inseguros quando percebem possíveis inconsistências e variações de atendimento comercial definidas pelos vendedores terceiros do site. O risco potencial incrementado conduz os consumidores a despender mais esforços para reduzir a incerteza no processo decisório.

Dentre os possíveis riscos associados às compras onlines (KIM; FERRIN; RAO, 2008; PAVLOU, 2003), estão: o risco em relação ao desempenho do vendedor; em virtude da privacidade de dados pessoais; em relação ao risco econômico envolvido; ou, ao risco psicológico.

Em primeiro lugar, dentre os riscos relacionados ao desempenho dos vendedores terceiros, alguns autores citam a falta de capacitação dos mesmos (HONG, 2015; JOLIVET; JULLIEN; POSTEL-VINAY, 2015). Nesse aspecto, a insegurança dos usuários em relação aos vendedores recai sobre a incapacidade de monitoramento do pedido (PAVLOU, 2003), e em riscos relacionados a falhas na entrega dos produtos ou serviços adquiridos, visto que o recebimento pode: sofrer atrasos; ser enviado a endereços errados; ou, com conteúdo incorreto e/ou faltando (HONG, 2015; KIM; FERRIN; RAO, 2008).

Em segundo lugar estão os riscos ocasionados pela disponibilização dos dados pessoais dos consumidores aos vendedores desconhecidos. Muitos estudos (GEFEN, 2000; KIM; FERRIN; RAO, 2008; KIM; KOO, 2016; WU; HUANG; FU, 2011)concordam que informações cedidas a comerciantes (com alta profissionalização ou não) podem ser facilmente utilizados em benefício próprio para fins maliciosos ou resignados a outras empresas interessadas em utilizar esses dados pessoais. Os prejuízos podem inclusive recair para perdas financeiras no momento em que aquele sujeito que se aproveitou do uso de informações do cartão de crédito (PAVLOU, 2003).

Sendo assim, em terceiro lugar, os riscos econômicos são aqueles usualmente associados a potenciais perdas monetárias em meio a transações em lojas virtuais (PAVLOU, 2003). No entanto, apesar de muitas pesquisas relatarem efeitos até mais fortes que os demais riscos envolvidos (JACOBY; KAPLAN, 1972), os riscos econômicos podem ser estendidos não só 
aspecto monetário, mas também, considerando o tempo perdido e o custo de oportunidade (KIM; FERRIN; RAO, 2008).

Por fim, autores relatam a possibilidade de riscos psicológicos envolvidos nas compras online. A percepção de insegurança a respeito do cumprimento dos acordos de compra pode gerar sentimentos como: ansiedade (HWANG; KIM, 2007), desconforto (HONG, 2015) e medo (HONG; CHO, 2011).

\section{4 \\ Confiança}

A confiança dos consumidores em ambientes virtuais é mencionada na literatura (BA; PAVLOU, 2002; JARVENPAA; TRACTINSKY; SAARINEN, 1999; LU et al., 2016; OLIVEIRA et al., 2017; PAVLOU, 2003) como elemento crucial nas intenções ou não de comportamento de compra. E como Pavlou (2003) bem coloca, praticamente todas transações requerem algum tipo de elemento que envolva confiança, em especial, processos de decisão de compra dentro de ambientes virtuais.

Em transações comerciais digitais, a confiança envolve uma relação de um para um, entre compradores e vendedores (OLIVEIRA et al., 2017). Os indivíduos podem formá-la a partir de uma crença de que as partes envolvidas na transação irão agir bem intencionadas, mesmo que o processo de formação de confiança envolva a aceitação de alguns riscos envolvidos (HONG; CHO, 2011), ou a partir da disposição de uma parte ser vulnerável às ações de outras partes (WU et al., 2015). Sendo assim, a falta de confiança dos usuários atua como um inibidor em transações comerciais com vendedores (OLIVEIRA et al., 2017).

Uma vez que o nível de confiança em um vendedor se sobrepõe ao risco percebido, o consumidor somente irá prosseguir se por meio de uma relação arriscada para seus interesses (MAYER; DAVIS; SCHOORMAN, 1995). Para Jarvenpaa, Tractinsky e Saarinen (1999), se um consumidor percebe que o vendedor é confiável, esse nível de confiança irá reduzir sua percepção de risco naquela transação. Sendo assim, a confiança exerce um papel importante na formação de atitudes positivas em compras online, reduzindo incertezas e fornecendo expectativas favoráveis para o comportamento de compra (PAVLOU, 2003).

Em plataformas de $e$-marketplaces, a confiança atua como uma crença global em torno do grupo de vendedores acerca de seu comprometimento com as promessas da loja intermediária (PAVLOU; GEFEN, 2004). Isso ocorre muito por conta das possibilidades asseguradas pelos sistemas de gestão e interface dos sites, garantindo usabilidade e 
confiabilidade aos usuários (GEFEN, 2000). Como benefício, a confiança pode reduzir tempo e esforço que os compradores devem dedicar para selecionar um vendedor adequado aos seus interesses (KIM et al., 2012; PAVLOU, 2003).

Kim e Peterson (2017) alertam para desafios constantes no consumo online e o papel da confiança em seu desenvolvimento. Nesse sentido, Chiu et al. (2014) sugerem que para lojas virtuais converterem potenciais compradores em clientes frequentes, os sites devem entregar diversos elementos que inspirem confiança (segurança, privacidade e ordem) em conjunto com todos os benefícios utilitários que uma loja virtual possa oferecer. Resultados de estudos indicam que tanto as percepções de qualidade acerca do site, quanto a marca/nome da loja virtual afetam a confiança dos consumidores e sua intenção de compra (CHANG; CHEN, 2008).

Assim, os sistemas de avaliação dos sites de compra surgem como uma fonte de informação valiosa, que, se os usuários julgarem úteis e com credibilidade, ajudam na formação de confiança (SHAN, 2016), visto que reduzem as incertezas em relação às promessas de qualidade e serviços das lojas intermediárias e vendedores (BA; PAVLOU, 2002). Da mesma forma, esses tipos de fontes de informação que por ventura não forem percebidos positivamente, implicam na formação de desconfiança sob a loja e os vendedores (GEFEN, 2000).

Visto que a confiança atua como um elemento essencial nas transações onlines, Kim, Ferrin e Rao (2008) sugerem o amplo entendimento dos antecedentes e bases de formação da confiança. Mais recentemente, Oliveira et al., (2017) demonstram a origem da confiança a partir de um complexo construto, formado desde características individuais dos consumidores, passando por percepções dos usuários perante as lojas e na interação da relação com a qualidade dos serviços prestados.

Colocadas as devidas considerações sobre avaliações de vendedores, é necessário analisá-las de acordo com as teorias de antecedentes da confiança. Grande parte da academia se orienta de acordo com os trabalhos de (MAYER; DAVIS; SCHOORMAN, 1995; MCKNIGHT; CUMMINGS; CHERVANY, 1998), nos quais a confiança se forma através dos fatores de percepção de confiabilidade: benevolência, integridade e competência. Sendo que, Hwang e Kim (2007) empiricamente vinculam os construtos de integridade e competência com aspectos que envolvem como intrínsecos os comportamentos comerciais dos vendedores, e, de modo que a benevolência atrelada à boas intenções do comerciante.

Por outro lado, algumas pesquisas (LU; FAN; ZHOU, 2016; OLIVEIRA et al., 2017) mostram outros antecedentes da confiança, como por exemplo, aspectos sociais que favorecem o ambiente online para promover a interação entre usuários, e estes, com vendedores terceiros. 
Em sua meta-análise, por exemplo, Kim e Peterson (2017) destacam os principais antecedentes na construção da confiança: percepção da qualidade do serviço, percepção de privacidade, reputação percebida e utilidade percebida. Outros exemplos são encontrados em Pavlou (2003), no qual percepções de funcionamento de estruturas institucionais explicam em grande parte a construção de confiança.

Apesar de pesquisas anteriores (GEFEN, 2000) não diferenciarem a avaliação da confiança dentro de um e-marketplace entre os vendedores terceiros e intermediários, cada um desses construtos pode ser interpretado de maneira diferente. Como Hong e Cho (2011) colocam, em plataformas do tipo e-marketplace os impactos da confiança podem diferir se analisados os construtos de confiança no intermediário e no vendedor em separado. A explicação lógica se dá pelo fato da presença de duas empresas perante o consumidor, emergindo possíveis crenças a respeito dos envolvidos pelo potencial comprador (HONG; CHO, 2011).

Em função da grande variedade de implicações e antecedentes da confiança, focaremos a análise da confiança entre as empresas envolvidas no processo de compra no e-marketplace: a confiança na loja intermediária e os vendedores terceiros que vendem através do site intermediador.

\subsection{1 \\ Confiança no intermediário}

E-marketplaces são plataformas que conectam compradores com vendedores, sendo que dentro desse modelo de negócio, as lojas intermediarias são basicamente agentes que fornecem um sistema de transação online e os serviços que permitem completar o procedimento (HONG, 2015). A partir daí, segundo Lu et al., (2016), a confiança no intermediário é derivada da dependência dos clientes em relação às ações da loja intermediadora e sua atuação na mediação de transações em sua plataforma de e-marketplace.

Resultados evidenciam a importância do comportamento diretamente interligado com as atuações das lojas intermediadoras (LU et al., 2016), cruciais na percepção de confiança e com impactos nas intenções de compra. Ao contrário dos conceitos de confiança em compras virtuais formulados apenas direcionados à possiblidade de consumo em lojas independentes, estudos anteriores (HONG, 2015; LU et al., 2016) examinam a atuação de lojas intermediárias na governança das interações entre vendedores e compradores. 


\subsection{2 Confiança no vendedor}

De acordo com $\mathrm{Lu}$ et al. (2016), consumidores necessitam confiar tanto na empresa intermediadora quanto nos vendedores terceiros em ambientes de compra e-marketplaces. $\mathrm{O}$ atendimento dessa necessidade é crucial para o futuro das estratégias das lojas intermediadoras assegurarem incertezas e gerir suas ações com devido controle (KIM; FERRIN; RAO, 2008).

A confiança nos vendedores de plataformas do tipo e-marketplace estão associadas diretamente às consequências das transações de fato (LU et al., 2016). Nesse sentido, a confiança pode ser impactada pelos riscos associados ao comportamento dos vendedores terceiros na plataforma: desconhecimento da empresa (KIM; AHN, 2006); incapacidade de atendimento conforme baixa profissionalização (HONG, 2015); e, desconfiança a respeito da aderência aos procedimentos acordados entre as instituições comerciais (HONG; CHO, 2011).

\section{5 Modelo conceitual}

Dadas as características dos e-marketplaces (HONG, 2015), as incertezas do ambiente (PAVLOU, 2003) e em relação aos vendedores (GEFEN; CARMEL, 2013), a intenção de compra dos consumidores tem indícios que é impactada a partir das barreiras apresentadas dentro desse modelo de negócio. No mesmo sentido que Kim et al. (2008), ao contrário de diversas pesquisas que comparam desempenhos de empresas e estratégias de vendas, este estudo se propõe a analisar as intenções dos consumidores, eliminando as limitações de analise somente via transações bem sucedidas. Adicionalmente, pesquisas que vão de encontro ao consumidor para estudos sobre o comportamento de compras online são indicadas por Gefen e Pavlou (2012).

\subsection{1}

\section{A reputação da loja terceira e a percepção de risco}

Resultados de pesquisas anteriores mostram que informações de outros consumidores, incluindo avaliações sobre experiências e vendedores, são importantes fatores na formação de como usuários acreditam nas informações e quanto de credibilidade os anúncios parecem a eles (FLANAGIN et al., 2014).

Em outros estudos, a reputação é avaliada em comparação com preços dos produtos. De maneira indireta, Wu et al. (2015) indicam que a dispersão de preços é percebida como 
medidora de qualidade entre os ofertantes, nas quais os vendedores posicionados nas extremidades das variações de preços oferecem riscos ao consumidor devido à natureza do modelo de negócio e a assimetria de informação em questão. Por outro lado, estudos procuram avaliar diretamente a relação conjunta entre preços e reputação dos vendedores e seus impactos nas atitudes em relação às composições. Os resultados mostram que reputações de vendedores são altamente relevantes na redução de risco percebido, tanto para preços baixos quanto para altos (WU; HUANG; FU, 2011). Assim, considera-se a hipótese:

Hipótese 1: A reputação do vendedor afeta de maneira direta e negativa a percepção de risco.

\subsection{2}

\section{A reputação das lojas terceiras com a confiança no intermediário e nas lojas terceiras}

A percepção de boa reputação tem sido discutida na literatura como uma força indissociável de construção de confiança (KIM; PETERSON, 2017). Da mesma forma, Fang et al. (2014) reconhecem a reputação dos vendedores como uma das variáveis de controle que afetam a confiança dos consumidores em lojas online, sendo ela, a mais forte.

Muitos estudos buscam oferecer de maneira empírica fontes de relações entre sistemas de avaliações com diversos tipos de comportamentos dos consumidores virtuais. Flanagin et al. (2014) buscaram entender como consumidores percebem as informações de canais de venda online e quão confiáveis elas são, principalmente os sistemas de avaliação. Seus resultados mostram que produtos com média de avaliações altas, possuem efeitos positivos na percepção de alta qualidade e intenção de compra de usuários.

Sendo assim, as duas hipóteses são propostas:

Hipótese 2: A reputação da loja afeta de maneira direta e positiva na confiança do consumidor com a loja intermediária.

Hipótese 3: A reputação da loja afeta de maneira direta e positiva na confiança do consumidor com a loja terciária.

\subsection{3}

\section{A percepção de risco com a confiança no intermediário e na loja terceira}

Segundo Chang e Chen (2008), consumidores procuram se ater a detalhes nas lojas onlines que sugiram experiências positivas ao realizar transações. Assim, segundos os autores, a confiança e o risco percebido são os principais construtos orientados cognitivamente e 
afetivamente na busca de evitar passar por experiências ruins. Para Cocosila e Trabelsi (2016), a percepção de risco geral sobre a experiência de compras onlines atua diretamente na adoção de seu comportamento e uso de tecnologias.

No entanto, para Kim e Koo (2016), a percepção de risco atua de maneira indireta nas intenções de compra influenciando diretamente e negativamente a confiança. Da mesma forma, Wu et al. (2015) apontam como a dispersão de preços em plataformas C2C aumentam a percepção de risco, e, consequentemente, diminuem a confiança dos consumidores.

Em suma, assim como as pesquisas anteriores, Hong (2015) afirma que a percepção de risco pode ser conexa com efeitos diretos e negativos na confiança dos consumidores. Nesse sentido, verificado os indícios na literatura, as duas hipóteses são propostas:

Hipótese 4: O risco percebido afeta de maneira direta e negativa na confiança do consumidor com a loja intermediária.

Hipótese 5: O risco percebido afeta de maneira direta e negativa na confiança do consumidor com a loja terciária.

\subsection{4 \\ Confiança no intermediário com confiança no vendedor terceiro}

Quando oferecem uma plataforma e serviços que facilitam transações, plataformas de marketplace online podem reduzir incertezas e favorecer um ambiente confiável para consumidores (PAVLOU; GEFEN, 2004). Ao aderirem a lojas intermediadoras, vendedores terceiros aceitam as condições daquela instituição e compartilham o mesmo objetivo (LU et al., 2016).

Segundo Stewart (STEWART, 2003), a confiança dos consumidores pode ser transferida para determinado agente a partir de outro contexto relativo. Em ambientes virtuais, como marketplaces onlines onde lojas intermediárias conectam consumidores com vendedores, existe a possibilidade de transferência de confiabilidade entre lojas intermediadoras para a comunidade de vendedores presentes em sua plataforma (PAVLOU; GEFEN, 2005; VERHAGEN; MEENTS; TAN, 2006).

Desta forma, considera-se a hipótese:

Hipótese 6: A confiança no intermediário afeta de maneira direta e positiva a confiança na loja terceira.

\subsection{5}

A confiança e a intenção de compra 
Lu et al. (2016) mostram que a confiança não só é transferida de intermediários para vendedores, mas como também encorajam os potenciais clientes a usarem a sua plataforma. Em ambientes de compras virtuais, consumidores procuram reduzir riscos e maximizar suas escolhas indo de encontro ao melhor comerciante disponível (HONG, 2015). Sendo assim, percepções de confiança são importantes fatores em ambientes de compras online nos quais consumidores estão expostos a riscos, e a sua falta atua como um inibidor em transações comerciais (OLIVEIRA et al., 2017; PAVLOU, 2003).

Quando percebem que o papel das lojas intermediárias em marketplaces onlines são cumpridos e eficientes, os consumidores se sentem mais confiantes em realizar transações por meio da loja virtual (PAVLOU; GEFEN, 2005). Por outro lado, Hong (2015) procura entender em que situações um consumidor seleciona uma plataforma de $e$-marketplace para efetuar uma compra por meio de antecedentes relacionados a envolvimento com o produto e a percepção de risco. Os resultados indicam que a confiança é um fator chave na decisão de compra entre uma plataforma de marketplace online e em um comerciante virtual que entrega diretamente ao consumidor sem intermediários. Quando e-marketplaces são comparados a lojas independentes, quanto maior a insegurança do consumidor, maior a necessidade de comprar via loja independente (HONG, 2015).

Portanto, são propostas as seguintes hipóteses:

Hipótese 7: A confiança na loja intermediária afeta de maneira direta e positiva a intenção de compra do consumidor.

Hipótese 8: A confiança na loja terceira afeta de maneira direta e positiva a intenção de compra do consumidor.

\subsection{6 \\ Modelo conceitual proposto}

Tendo em vista a necessidade de teste das hipóteses anunciadas anteriormente, o modelo conceitual abaixo é proposto para verificar a importância relativa das reputações dos vendedores terceiros dentro de plataformas de $e$-marketplaces e seus impactos na intenção de compra. 


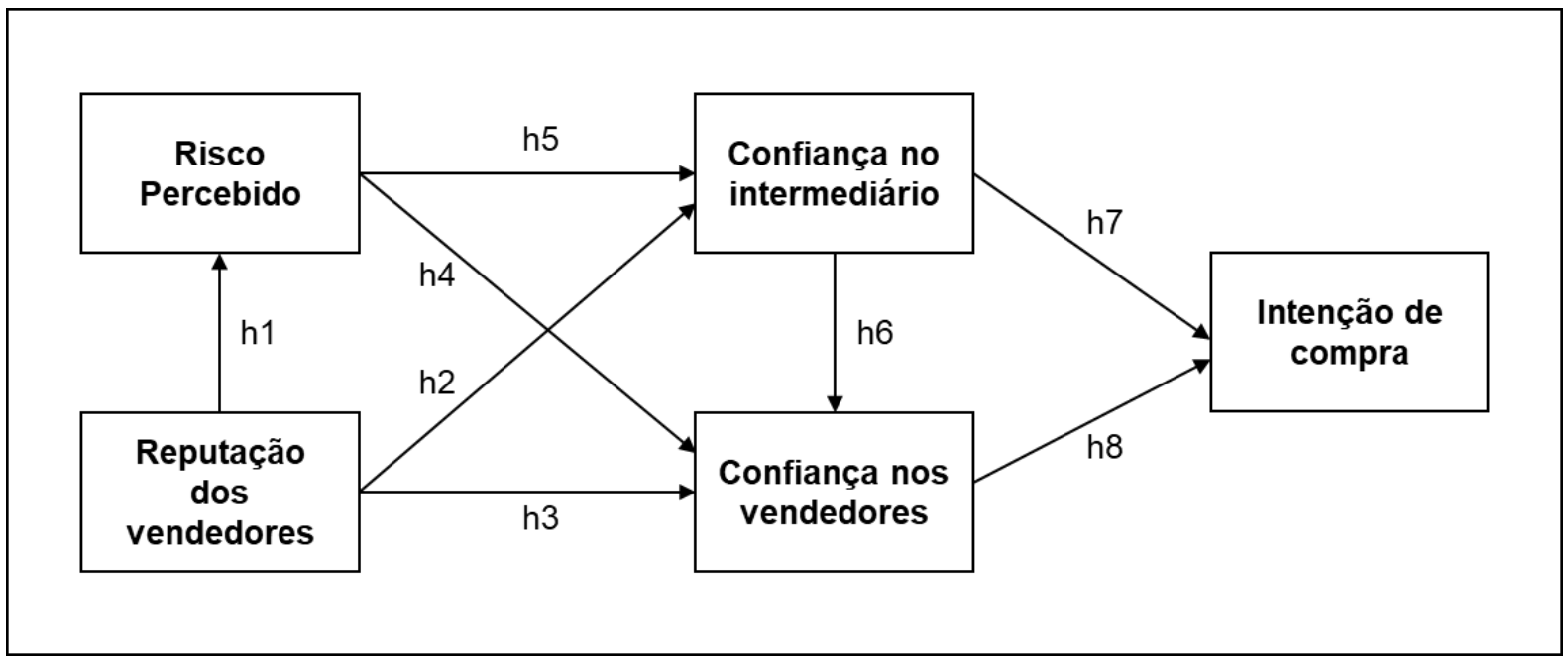

Figura 1: Modelo conceitual proposto

Fonte: Própria

\section{6 \\ Modelo conceitual rival}

No modelo anterior, foi considerado o fluxo de relações entre risco percebido impactando a confiança. Neste modelo rival, a relação desses construtos é baseada conforme pesquisas anteriores que propõe a confiança como antecedente do risco percebido (CHANG; CHEN, 2008; KIM; KOO, 2016; MITCHELL, 1999; PAVLOU, 2003).

\subsection{1}

\section{A confiança e o risco percebido}

Como Bauer (1961) coloca, uma fonte confiável ajuda consumidores avaliarem de maneira subjetiva sua percepção de risco. Quando observados ambientes virtuais de compra, a confiança reduz incertezas acerca dos comportamentos dos vendedores e os riscos associados (PAVLOU, 2003). Na prática, o desempenho de intermediários são altamente relacionados as ações que envolvem a redução do risco percebido em sua plataforma e vendedores presentes nela (VERHAGEN; MEENTS; TAN, 2006).

Sendo assim, Kim et al. (2008) indicam que a confiança dos consumidores atua em lojas virtuais de maneira fundamental, onde não só reduz o risco percebido impactando a intenção de compra de maneira indireta, mas também, confirma a hipótese de efeitos positivos diretos, como visto no item 2.5.5. Portanto, consideram-se as hipóteses:

Hipótese 9: A confiança na loja intermediária afeta de maneira direta e negativa o risco percebido. 
Hipótese 10: A confiança na loja terceira afeta de maneira direta e negativa o risco percebido.

\subsection{2}

\section{O risco percebido e a intenção de compra}

Também é discutida na literatura a relação entre a percepção de risco e seus impactos no comportamento do consumidor. Kim et al. (2008) oferecem evidencias de que os riscos percebidos pelos consumidores reduzem suas intenções de compra. Da mesma forma, para Pavlou (2003), o risco percebido assume um papel importante no consumo online e está altamente relacionado a comportamentos de compra dos consumidores. Sendo assim, considera-se a hipótese:

Hipótese 11: O risco percebido afeta de maneira direta e negativa a intenção de compra.

\subsection{3}

Modelo conceitual rival proposto

Sendo assim, tendo como base o modelo da figura $1 \mathrm{e}$ as prerrogativas discutidas no subitem anterior, as hipóteses h4, h5 são removidas e incluídas as hipóteses h9, h10 e h11. O modelo conceitual rival proposto neste estudo se apresenta conforme a seguir.

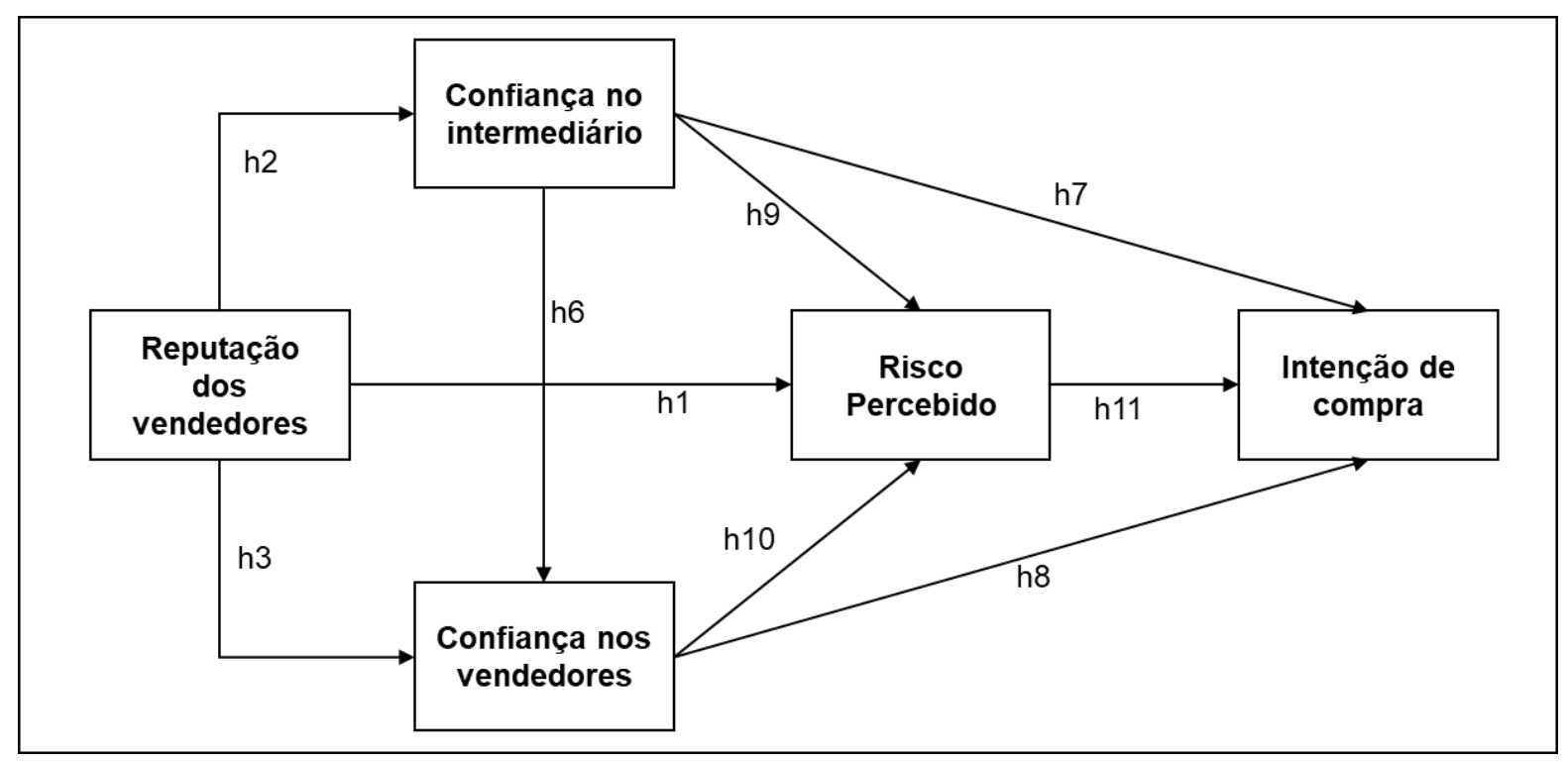

Figura 2: Modelo conceitual alternativo proposto Fonte: Própria 


\section{3 \\ Método}

Neste capítulo são apresentados o detalhamento do método, bem como suas características e justificativas de escolha para os testes das hipóteses apresentadas no capítulo anterior. A seguir, são descritos o tipo de pesquisa, a operacionalização das variáveis, o procedimento de coleta de dados, o tratamento e a análise estatística dos dados, e, as limitações do método.

\section{1}

\section{Tipo de pesquisa}

A grande maioria de pesquisas sobre o comportamento de compra de consumidores em e-commerce são de natureza empírica, segundo Oliveira et al. (2017), concentrando abordagens metodológicas dos tipos survey e experimentos. O presente estudo segue esta linha, realizando a aplicação de uma cross-sectional survey, cuja principal característica se resume na observação de um fenômeno uma vez para cada fonte em um curto espaço de tempo (MALHOTRA, 2010).

A opção por aplicação de survey frente a experimentos é baseada conforme meta-analise de Kim e Peterson (2017), que, destacam que embora experimentos sejam capazes de oferecer evidencias mais conclusivas quando comparadas com surveys, as modificações artificiais para a aplicação do método resultam em limitações para validações e aplicações externas ao experimento em si.

Com o intuito de que todos os respondentes tenham o mesmo entendimento a respeito do vocabulário utilizado no questionário e a correta identificação dos sujeitos de pesquisa (vendedores terceiras e intermediários), foi colocado um texto de apresentação no cabeçalho do questionário juntamente com uma figura reproduzindo uma página de compra do site Americanas.com. Com o intuito de selecionar apenas aqueles respondentes que realmente compreenderam e identificaram os papéis dos agentes envolvidos em uma operação de marketplace online, foram filtradas as respostas que não satisfizeram esta condição quantificados no item 4.1. A escolha por esta loja online remete às justificativas apresentadas no item 1.4, a apresentação do questionário é exemplificada no apêndice A no capítulo 7.

\section{2}

\section{Operacionalização das variáveis}




\subsection{1 \\ Definição Operacional das variáveis}

Essa pesquisa foi elaborada a partir de uma adaptação do modelo proposto por Wu et al. (2015) aliado a escalas escolhidas em produções acadêmicas que envolveram os construtos do modelo conceitual desenvolvido. No quadro 1, são apresentadas as escalas de medição de cada construto do modelo proposto nesta pesquisa, bem como a quantidade de itens utilizados, os tipos de medida e os autores de origem.

\section{2 .2 \\ Procedimentos de tradução e Adaptação das escalas utilizadas}

As escalas utilizadas neste estudo foram reproduzidas originalmente em trabalhos publicados na língua inglesa. Desta forma, foi necessário a execução de uma tradução e adaptação de cada escala para a língua portuguesa, possibilitando que o processo de aplicação desta pesquisa alcançasse um número maior de brasileiros.

Segundo Sperber (2004), o processo de adaptação de escalas em outras línguas requer o seguimento de uma série de etapas, somente a tradução literal não é suficiente. Seguindo a proposta do autor, o questionário foi inicialmente traduzido por 2 profissionais fluentes na língua inglesa em separado, para, em seguida, ser revisado por um terceiro. Por fim, o resultado desse processo foi distribuído por especialistas no tema (acadêmicos e pesquisadores de comportamento do consumidor) com fluência na língua inglesa para validarem os resultados e formularem a back-translation do instrumento de pesquisa.

\subsection{3}

\section{Pré-teste do instrumento de pesquisa}

Com o intuito de validar a tradução das questões de pesquisa e corrigir eventuais incompreensões do questionário por parte dos respondentes, foi realizado um pré-teste com uma pequena amostra do público de interesse. 10 indivíduos foram abordados para que sinalizassem possíveis dúvidas em relação a apresentação e redação das questões de pesquisa, com respectivas sugestões de alteração. Ao final desse esforço, um novo teste foi realizado junto a 20 pessoas por meio da plataforma online, no qual foram testados a preferência dos participantes em torno de uma imagem exemplificando um marketplace ou um link de acesso para uma página real de uma oferta de um produto. Com as devidas considerações dos participantes, a imagem foi escolhida por ter atingido o objetivo mais facilmente, além de ser 
identificada como uma opção de carregamento mais rápido do questionário, evitando a perda de respondentes e agilizando o processo de coleta de dados.

As questões RP2 e RP3 originalmente eram constituídas em uma só pergunta, no entanto, foram colocadas em separado no questionário final, devido aos participantes do préteste relatarem que consideraram objetos em diferenciados (informações pessoais e métodos de pagamento). Sendo assim, outros pequenos ajustes com respeito a layout foram devidamente equacionados que resultaram no questionário de aplicação de pesquisa final que é apresentado conforme apêndice A. 
Quadro 1: Definição operacional das variáveis

\begin{tabular}{|c|c|c|c|}
\hline Construtos & Questões de pesquisa & $\begin{array}{c}\text { Tipo e } \\
\text { medidas de } \\
\text { escala }\end{array}$ & Referências \\
\hline $\begin{array}{l}\text { Reputação } \\
\text { do vendedor: }\end{array}$ & $\begin{array}{l}\text { Perguntas originais: } \\
\text { RV1. This store is well known. } \\
\text { RV2. This store has a bad reputation in the market. } \\
\text { RV3. This store has a good reputation. } \\
\text { Perguntas adaptadas para o questionário: } \\
\text { RV1. Esses vendedores terceiros são bem conhecidos. } \\
\text { RV2. Esses vendedores terceiros tem uma reputação ruim no mercado. } \\
\text { RV3. Esses vendedores terceiros tem uma boa reputação. }\end{array}$ & $\begin{array}{l}\text { Likert (escala } \\
\text { de 5); }\end{array}$ & $\begin{array}{l}\text { Jarvenpaa, } \\
\text { Tractinsky e } \\
\text { Saarinen } \\
\text { (1999) }\end{array}$ \\
\hline $\begin{array}{l}\text { Risco } \\
\text { percebido: }\end{array}$ & $\begin{array}{l}\text { Perguntas originais: } \\
\text { RP1. It is likely that the product I purchased on the website failed to meet the } \\
\text { performance requirements originally intended by the purchase. } \\
\text { RP2/3. It is likely that shopping on this website will cause me to lose control over the } \\
\text { privacy of my personal and payment information. } \\
\text { RP3. It is likely that shopping on this website will cause me to suffer a financial loss due } \\
\text { to the hidden costs, maintenance costs or lack of warranty in case of faults. } \\
\text { RP4. It is likely that the online seller may fail to deliver the product or make a late } \\
\text { delivery. } \\
\text { Perguntas adaptadas para o questionário: } \\
\text { RP1. É provável que o produto que eu possa comprar no marketplace online não } \\
\text { atende aos requisitos de desempenho originalmente previstos pela compra. } \\
\text { RP2. É provável que fazer compras neste marketplace online fará com que eu perca o } \\
\text { controle sobre a privacidade das minhas informações pessoais. } \\
\text { RP3. É provável que fazer compras neste marketplace fará com que eu perca o controle } \\
\text { sobre as minhas informações de métodos de pagamento. } \\
\text { RP4. É provável que a compra neste marketplace online fará com que eu sofra uma } \\
\text { perda financeira devido aos custos ocultos, custos de manutenção ou prejuízos por falta } \\
\text { de garantia em caso de falhas. } \\
\text { RP5. É provável que o vendedor terceiro deste marketplace online possa deixar de } \\
\text { entregar o produto ou efetuar uma entreqa além do prazo. }\end{array}$ & $\begin{array}{l}\text { Likert (escala } \\
\text { de 5); }\end{array}$ & $\begin{array}{l}\text { Featherman \& } \\
\text { Pavlou (2003); } \\
\text { Pires et al. } \\
\text { (2004) }\end{array}$ \\
\hline
\end{tabular}




\begin{tabular}{|c|c|c|c|}
\hline $\begin{array}{l}\text { Confiança no } \\
\text { Intermediário } \\
\text { : }\end{array}$ & $\begin{array}{l}\text { Perguntas originais: } \\
\mathrm{Cl} \text {. Even if not monitored, l'd trust the intermediary to do the job right. } \\
\mathrm{Cl} \text {. I trust the intermediary. } \\
\mathrm{Cl} \text {. I believe that the intermediary is trustworthy. } \\
\text { Perguntas adaptadas para o questionário: } \\
\text { Cl1. Mesmo se não fossem monitorados, eu confiaria que a loja intermediária } \\
\text { (Americanas.com) faria o trabalho direito. } \\
\mathrm{Cl} \text {. Eu confio na loja intermediária (Americanas.com). } \\
\mathrm{Cl} \text {. Eu acredito que a loja intermediária (Americanas.com) é confiável. }\end{array}$ & $\begin{array}{l}\text { Likert (escala } \\
\text { de 5); }\end{array}$ & $\begin{array}{l}\text { Mayer et al. } \\
(1995) \text { e Gefen } \\
(2000)\end{array}$ \\
\hline $\begin{array}{l}\text { Confiança no } \\
\text { vendedor } \\
\text { terceiro: }\end{array}$ & $\begin{array}{l}\text { Perguntas originais: } \\
\text { CT1. Even if not monitored, l'd trust the community of sellers to do the job right. } \\
\text { CT2. I trust the community of sellers. } \\
\text { CT3. I believe that the community of sellers is trustworthy. } \\
\text { Perguntas adaptadas para o questionário: } \\
\text { CT1. Mesmo se não fossem monitorados, eu confiaria que os vendedores terceiros } \\
\text { deste marketplace fariam o trabalho direito. } \\
\text { CT2. Eu confio nos vendedores terceiros deste marketplace. } \\
\text { CT3. Eu acredito que os vendedores terceiros são confiáveis. }\end{array}$ & $\begin{array}{l}\text { Likert (escala } \\
\text { de 5); }\end{array}$ & $\begin{array}{l}\text { Mayer et al. } \\
\text { (1995) e Gefen } \\
(2000)\end{array}$ \\
\hline $\begin{array}{l}\text { Intenção de } \\
\text { compra: }\end{array}$ & $\begin{array}{l}\text { Perguntas originais: } \\
\text { IC1. I would feel comfortable buying products from this online vendor. } \\
\text { IC2. I would feel comfortable seeking products information from this online vendor. } \\
\text { IC3. I would feel comfortable receiving free product information from this online vendor. } \\
\text { IC4. I would feel comfortable providing information to this online vendor in order to } \\
\text { receive customized service. } \\
\text { IC5. I would feel comfortable developing a valuable relationship with this online vendor. } \\
\text { Perguntas adaptadas para o questionário: } \\
\text { IC1. Eu me sentiria confortável em comprar produtos neste marketplace. } \\
\text { IC2. Eu me sentiria confortável a procurar informações de produtos neste marketplace. } \\
\text { IC3. Eu me sentiria confortável em receber informações gratuitas de produtos deste } \\
\text { marketplace. } \\
\text { IC4. Eu me sentiria confortável fornecendo minhas informações pessoais a este } \\
\text { marketplace a fim de receber um serviço personalizado. } \\
\text { IC5. Eu me sentiria confortável em desenvolver um relacionamento com este } \\
\text { marketplace. }\end{array}$ & $\begin{array}{l}\text { Likert (escala } \\
\text { de 5); }\end{array}$ & $\begin{array}{l}\text { Gefen }(2000) \text { e } \\
\text { Jarvenpaa } \\
\text { (2000) }\end{array}$ \\
\hline
\end{tabular}

Fonte: Própria 


\section{3 \\ População e amostra}

\subsection{1 \\ População e amostragem}

A população alvo deste trabalho é formada por brasileiros que possuíram ao menos uma experiência de compra online nos últimos 12 meses. Ao contrário de diversas pesquisas passadas (CABRAL; HORTAÇSU, 2010; CAI et al., 2014; JOLIVET; JULLIEN; POSTEL-VINAY, 2015), este trabalho buscou procurar diretamente a opinião de usuários ao invés de relacionar sistemas de reputação comparados com desempenho de vendas em determinada base de dados de empresas do setor.

Nesta pesquisa, foram aplicados procedimentos de amostragem por conveniência e por bola de neve. Conforme colocado por Black (2011), o processo de seleção de entrevistados na amostragem por conveniência é realizado conforme julgamento do pesquisador. Desta forma, esta opção acaba por realizar a distribuição dos questionários entre indivíduos ao alcance do pesquisador, demando menos tempo e recursos financeiros (MALHOTRA, 2010). No entanto, deve-se atentar o fato de que este tipo de amostragem tende a apresentar indivíduos com características próximas entre si e não necessariamente à população.

Por outro lado, a utilização da técnica de amostragem por bola de neve é bastante indicada em situações que se espera obter informações de uma população mais específica (compradores de comércio eletrônico). Ao solicitar que os respondentes indiquem a pesquisa para possíveis pessoas que são capazes de responder ao questionário (MALHOTRA, 2010), as chances de se obter respondentes interessados e capacitados são maiores. Hair et al. (2005) ainda ressaltam as vantagens de se trabalhar com esta amostragem, não somente na facilidade de obter respondentes qualificados, mas também dentro de um tempo reduzido com baixo custo.

\section{4}

\section{Coleta de dados}

Conforme colocado anteriormente, o instrumento de coleta de dados foi composto por 19 questões. Os dados da pesquisa foram coletados com o auxílio de 
ferramenta de survey online Qualtrics, no qual foi possível a exibição de fotos e textos explicativos sobre o assunto. Um convite para a participação na pesquisa acompanhado de um link para responder o questionário foi encaminhado via e-mail, redes sociais e aplicativos de mensagens instantâneas para possíveis respondentes, sendo estes respondentes solicitados a encaminhar o link para pessoas com perfil similar ao deles.

$\mathrm{O}$ instrumento de pesquisa situado no apêndice A foi distribuído por e-mail para cerca de 1000 indivíduos, divulgado dentro de redes sociais (Facebook e Linkedin), compartilhado por meio de aplicativo de mensagens instantâneas (Whatsapp) e publicado em blogs específicos com conteúdo para lojas online (MundoMarketplace e E-commerce Brasil). Embora o conteúdo desses sites fosse voltado para profissionais que trabalham com $e$-commerce, foi solicitado que o link de acesso ao questionário fosse encaminhado a clientes e pessoas que pudessem responder com imparcialidade a pesquisa. A coleta de dados iniciou-se em 16 de novembro de 2017 e se estendeu até 23 de dezembro do mesmo ano. A confidencialidade das informações foi informada a todos os respondentes que se dispuseram de participar voluntariamente.

\section{5 \\ Tratamento de dados}

Terminado o período de aplicação de questionários, os dados foram reunidos em uma base de dados SPSS para processamento estatístico. Nesta etapa de pesquisa o objetivo foi concentrado na limpeza e adequação dos dados para identificar e excluir informações que não atenderam de maneira completa os registros solicitados na pesquisa. Foram obtidos ao todo $309(56,3 \%)$ respondentes válidos de 549 questionários iniciados, sendo descartados: 138 (25,1\%) questionários incompletos, $48(8,7 \%)$ questionários respondidos de maneira incorreta - quando os respondentes não souberam apontar corretamente a loja intermediária e o vendedor terceiro; 54 (9,8\%) questionários com respostas inconsistentes - quando atributos como "ruim" e "bom" eram assinalados para perguntas similares. Após a conclusão desta tarefa foram analisadas as respostas referentes às variáveis demográficas para execução da caracterização da amostra da pesquisa. 


\section{6}

\section{Análise estatística}

Com o intuito de testar as hipóteses de pesquisa de ambos modelos propostos, foram utilizadas as técnicas de modelagem de equações estruturais (SEM), utilizando o software AMOS 21. A opção pela utilização de SEM faz sentido frente às questões de pesquisa colocadas, uma vez que analisam a estrutura de relações simultâneas entre construtos definidos (HAIR et al., 2005).

Para a análise estatística da pesquisa, foi adotada a abordagem de dois estágios para modelagem de equações estruturais, conforme sugerido por Byrne (2010), Hair et al. (2005) e Malhotra (2010). Na primeira etapa é avaliado o modelo de mensuração obtido por meio de uma análise fatorial confirmatória (CFA), método utilizado para verificar o quanto cada escala esteve associada a cada construto. A convergência das escalas de cada construto foi obtida por meio de sua confiabilidade composta (Composite Reliability - CR) e validade (com ajuda da Variância Extraída Média, Avarege Variance Extracted - AVE). Enquanto a avaliação de discriminação entre construtos foi feita por meio da montagem de uma Matriz de Validade Discriminante, uma comparação entre a AVE de cada construto com a variância compartilhada (o quadrado do coeficiente de correlação) entre todos os pares de construtos. Segundo Fornell e Larcker (1981), é verificada a validade discriminante uma vez que as variâncias compartilhadas são menores que as variâncias extraídas dentro dos construtos. Ao final desta etapa, os itens de pesquisa observados como indicadores ruins para responder por aquele construto são descartados para a obtenção de um melhor modelo de mensuração.

$\mathrm{Na}$ segunda etapa, no que diz respeito para avaliação dos modelos estruturais, foram considerados os índices sugeridos na literatura acadêmica (HAIR et al., 2005; MALHOTRA, 2010; PAVLOU; GEFEN, 2004): a estatística chiquadrada do modelo juntamente com os graus de liberdade associados $\left(\chi^{2} /\right.$ d.f $)$, o Tucker-Lewis Index (TLI), o Comparative Fit Index (CFI), o Root Mean Squared Approximation Error (RMSEA), o Standerized Root Mean Square Residual (SRMSR), e o Parsimony Normed Fit Index (PNFI).

\section{7}

\section{Limitações do método}




\subsection{1 \\ Relacionadas ao critério da amostragem}

A delimitação da amostra consiste de brasileiros que tenham compreendido o papel dos agentes em uma operação de marketplace online. Tendo em vista a seleção por conveniência, a amostra apresentou níveis de escolaridade e renda familiar superior à média da população brasileira.

\section{7 .2}

\section{Relacionadas à coleta de dados}

A aplicação de um questionário online implica na renúncia de segurança da pesquisa sobre a atenção e dedicação dos respondentes junto ao que está sendo perguntado (MALHOTRA, 2010). Em virtude do tema abordado, a apresentação do tema no instrumento de pesquisa foi bastante extensa e trouxe consigo um expressivo número de abandonos de questionários indicando cansaço e frustração dos respondentes. Sendo assim, dentro da amostra daqueles respondentes que foram até o final da pesquisa, também podemos supor que em algumas marcações de respostas tiveram algum desleixo.

Ainda em relação ao instrumento de pesquisa, o pré-teste indicou uma preferência dos respondentes para a exibição de um exemplo de marketplace online por meio de uma imagem. Uma possível limitação deste estudo recai sobre a experiência limitada dos respondentes com os marketplaces na prática, visto que a opção por um link de acesso para uma página real foi muito criticada pela demora e necessidade de alternar páginas seja qual for o dispositivo de resposta (computador ou celular).

Não obstante, em uma das plataformas sociais (LinkedIn) usadas para a coleta de dados, os respondentes possuíam um conhecimento maior do que os demais (abordados em outras mídias) em relação a marketplaces online. Em virtude do interesse em relação ao assunto nesta plataforma em particular (foram abordadas pessoas que trabalham diretamente com e-commerce), é possível que os respondentes vindos do LinkedIn possuíssem vieses em relação ao modelo de marketplace como um todo, por exemplo: pessoas que trabalham para um marketplace possivelmente avaliaram bem as reputações e não perceberam riscos; 
ou o contrário, pessoas que são avessas a ideia de adoção ao modelo de marketplace avaliariam consequentemente mal as reputações e intenções de compra.

Outra possível limitação em relação à coleta de dados pode ser relacionada à utilização de uma simulação da página da loja online da Americanas.com na pesquisa. Uma vez que a pesquisa não garantiu que os respondentes estivessem livres de quaisquer vínculos empregatícios ou judiciais, por exemplo. Sendo assim, esse estudo não deve generalizar resultados para todo e qualquer marketplace online. 


\section{4 \\ Modelagem e análise de dados}

Neste capítulo são abordados os resultados em conformidade com as propriedades estatísticas da amostra coletada, bem como os modelos de mensuração e estruturais propostos. Ao fim, as hipóteses de pesquisa são testadas e os resultados de cada modelo são comparados.

\section{1 Caracterização da amostra}

A tabela 4.1 ilustra as características da amostra final conforme algumas estatísticas descritivas. Do total de 309 participantes, 188 eram do sexo masculino $(60,8 \%)$ e 121 do sexo feminino $(39,2 \%)$. Em relação à idade, a média observada foi de 33,8 anos e a faixa etária com maior número de respondentes foi entre 25 e 45 anos $(56,6 \%)$. Em termos de renda familiar média, 42,7\% dos participantes indicaram renda superior a 10.000 reais enquanto outros $21,7 \%$ afirmaram receber entre 6.000 e 10.000 reais. No que diz respeito à escolaridade, a maior parte da amostra respondeu que possuía nível superior completo ou incompleto $(52,1 \%)$ com outros $42,1 \%$ indicando pós-graduação completa ou incompleta. Observando os hábitos de compra, 194 participantes $(62,8 \%)$ responderam ter comprado em pelo menos 4 sites de compras online nos últimos 12 meses enquanto apenas 38 participantes $(12,3 \%)$ indicaram ter comprado algum bem ou serviço em uma loja online.

Tabela 1: Características da Amostra

\begin{tabular}{ccc}
\hline Característica & Descrição & $\begin{array}{c}\text { Porcentagem de } \\
\text { todos os } \\
\text { respondentes }\end{array}$ \\
\hline Sexo & Masculino & $188(60,8 \%)$ \\
& Feminino & $121(39,2 \%)$ \\
\hline \multirow{3}{*}{ Idade } & $<=25$ & $75(24,3 \%)$ \\
& $25<e<=45$ & $175(56,6 \%)$ \\
& $>45$ & $59(19,1 \%)$ \\
& Média & 33,8 \\
Mínimo & 16 \\
Mediana & 30
\end{tabular}




\begin{tabular}{ccc} 
& Máximo & 70 \\
\hline & Até 1.000 & $3(1,0 \%)$ \\
& Entre 1.000 e 2.000 & $21(6,8 \%)$ \\
Renda (R\$) & Entre 2.000 e 3.500 & $28(9,1 \%)$ \\
& Entre 3.500 e 6.000 & $58(18,8 \%)$ \\
& Entre 6.000 e 10.000 & $67(21,7 \%)$ \\
& Acima de 10.000 & $132(42,7 \%)$ \\
\hline & & 0 \\
\hline & Fundamental & $18(5,8 \%)$ \\
& Médio & $161(52,1 \%)$ \\
\hline & Graduação & $130(42,1 \%)$ \\
\hline Número de sites que & Pós-graduação & $0(0 \%)$ \\
efetuou compra nos & 0 & $38(12,3 \%)$ \\
últimos 12 meses & 1 & $26(8,4 \%)$ \\
& 2 & $51(16,5 \%)$ \\
\hline Fonde & 3 & $194(62,8 \%)$ \\
\hline
\end{tabular}

Fonte: Própria

\section{2}

\section{Análise e resultados}

\subsection{1 \\ Análise do modelo de mensuração}

A análise do modelo de mensuração têm como objetivo básico estabelecer a força das variáveis observadas (por meio das escalas utilizadas no instrumento de pesquisa) com os construtos latentes não observados, que compõe posteriormente os construtos de suporte das hipóteses desta pesquisa. Segundo Hair et al., (2005), a análise do modelo de mensuração ainda deve atender as premissas de validade de face, nomológica, confiabilidade, unidimensionalidade e discriminante.

\subsubsection{1}

\section{Ajuste geral do modelo de mensuração}

Tendo em vista a necessidade de testar a validade, unidimensionalidade e confiabilidade das escalas utilizadas no modelo de mensuração, foi conduzida uma análise fatorial confirmatória (CFA). O modelo foi testado inicialmente com todos os 19 itens presentes no instrumento de pesquisa e apresentou bons índices de avaliação: valor significativo para índice qui-quadrado $\left(\chi^{2}=394,77\right.$, d.f. $=142$, p < 
$0,001, \chi^{2} /$ d.f. $=2,780$ ); CFI de 0,903; IFI de 0,904; TLI de 0,883; RMSEA de 0,076; e SRMR de 0,0665 .

No entanto, após esta análise inicial, o modelo foi refinado e ficou constatado que 3 itens do instrumento de pesquisa impediam a validade de unidimensionalidade dos construtos, sendo eles: RV1, RP1 e RP5. Após a exclusão destes, houve uma pequena diminuição dos resultados obtidos no modelo de mensuração, mas dentro de valores razoáveis como sugerem Hair et al. (2005). O modelo com os 16 itens selecionados apresentou: valor significativo para índice qui-quadrado $\left(\chi^{2}=314,87\right.$, d.f. $=94, p<0,001, \chi^{2} /$ d.f. $\left.=3,350\right)$; CFI de 0,909; IFI de 0,910; TLI de 0,901; RMSEA de 0,080; e SRMR de 0, 0701.

\subsubsection{4}

\section{Validade de face e nomológica}

Segundo Hair et al., (2005), a validade de face corresponde à consistência do conteúdo de cada item com o construto que mede ele mesmo. Este requisito foi executado durante a escolha das escalas utilizadas neste estudo ao optar pela escolha de escalas já utilizadas em artigos acadêmicos de relevância relacionados com o universo de compras online.

Por outro lado, a validade nomológica busca examinar se as correlações entre construtos estão de acordo com a literatura acadêmica em questão (HAIR et al., 2005). O quadro 2 facilita a comparação e análise entre os resultados obtidos. Conforme a literatura já indicava, todas as correlações que envolveram o construto Risco Percebido são negativas. Ora, uma vez que este é o único construto que é visto como prejudicial ao comportamento de todos os outros, os resultados obtidos fazem todo sentido. Também é possível verificar que os construtos que envolvem Confiança possuem relação direta e positiva com demais construtos. Enquanto a percepção de uma boa Reputação dos Vendedores terceiros também causa o mesmo efeito. Neste quadro, também podemos observar que a correlação mais forte é verificada entre o construto de Risco Percebido e Intenção de Compra. 
Quadro 2: Matriz de Correlação entre Construtos

\begin{tabular}{|c|c|c|c|c|c|}
\cline { 2 - 6 } \multicolumn{1}{c|}{} & $\begin{array}{c}\text { Reputação } \\
\text { dos } \\
\text { vendedores }\end{array}$ & $\begin{array}{c}\text { Risco } \\
\text { Percebido }\end{array}$ & $\begin{array}{c}\text { Confiança no } \\
\text { intermediário }\end{array}$ & $\begin{array}{c}\text { Confiança } \\
\text { no } \\
\text { vendedor } \\
\text { terceiro }\end{array}$ & $\begin{array}{c}\text { Intenção } \\
\text { de } \\
\text { compra }\end{array}$ \\
\hline $\begin{array}{c}\text { Reputação } \\
\text { dos } \\
\text { vendedores }\end{array}$ & $\mathbf{1}$ & $-0,321$ & 0,223 & 0,467 & 0,428 \\
\hline $\begin{array}{c}\text { Risco } \\
\text { Percebido }\end{array}$ & $-0,321$ & $\mathbf{1}$ & $-0,342$ & $-0,360$ & $-0,602$ \\
\hline $\begin{array}{c}\text { Confiança no } \\
\text { intermediário }\end{array}$ & 0,223 & $-0,342$ & 1 & 0,306 & 0,445 \\
\hline $\begin{array}{c}\text { Confiança no } \\
\text { vendedor } \\
\text { terceiro }\end{array}$ & 0,467 & $-0,360$ & 0,306 & $\mathbf{1}$ & 0,527 \\
\hline $\begin{array}{c}\text { Intenção de } \\
\text { compra }\end{array}$ & 0,428 & $-0,602$ & 0,445 & 0,527 & $\mathbf{1}$ \\
\hline
\end{tabular}

Fonte: Própria

\subsubsection{2 \\ Validade convergente}

A unidimensionalidade é demonstrada quando os indicadores de um construto têm ajustes aceitáveis sobre um modelo de um só fator unidimensional (HAIR et al., 2005). O uso do Alpha de Cronbach, sugerido acima de 0,7, não garante a unidimensionalidade, mas indica que ela existe. Tendo isso em vista, usamos a Confiabilidade Composta (CR) como uma medida da consistência interna ao qual os indicadores respondem por aquele construto, comumente sugerido pela academia como acima de 0,7 (HAIR et al., 2005).

A Variância Média Extraída explica a quantia geral de variância nos indicadores que representam o construto latente. A maioria dos autores orienta que tais medidas devem ser superiores ao nível de 0,5 (HAIR et al., 2005). Todos os valores de AVE obtidos para os construtos utilizados foram satisfatórios $(0,5 \mathrm{ou}$ maior). O resumo dos índices obtidos é exibido na tabela 2 a seguir. 
Tabela 2: Análise de Confiabilidade, Confiabilidade Composta e Variância Média Extraída

\begin{tabular}{lccc}
\hline \multicolumn{1}{c}{ Construto } & $\begin{array}{c}\text { Alpha de } \\
\text { Cronbach (a) }\end{array}$ & $\begin{array}{c}\text { Confiabilidade } \\
\text { composta (CR) }\end{array}$ & $\begin{array}{c}\text { Variância Média } \\
\text { Extraída (AVE) }\end{array}$ \\
\hline $\begin{array}{l}\text { Reputação dos } \\
\text { vendedores }\end{array}$ & 0,848 & 0,832 & 0,63 \\
$\begin{array}{l}\text { Risco Percebido } \\
\begin{array}{l}\text { Confiança no } \\
\text { intermediário }\end{array}\end{array}$ & 0,727 & 0,851 & 0,66 \\
$\begin{array}{l}\text { Confiança no } \\
\text { vendedor } \\
\text { terceiro } \\
\text { Intenção de } \\
\text { compra }\end{array}$ & 0,782 & 0,864 & 0,56 \\
\hline
\end{tabular}

Fonte: Própria

\subsubsection{3}

\section{Validade discriminante}

Segundo Fornell e Larcker (1981), a validade discriminante tem o objetivo de verificar o grau de afinidade das variáveis de pesquisa dentro de seu construto quando comparadas com demais construtos latentes. Os autores sugerem que esta análise seja feita por meio da comparação da variância extraída média contra a variância compartilhada (o quadrado do coeficiente de correlação) entre todos os pares de construtos. O quadro 3 a seguir indica validade discriminante adequada para este estudo já que a AVE de cada construto é superior às variâncias compartilhadas observadas.

Quadro 3: Matriz de Validade Discriminante

\begin{tabular}{|c|c|c|c|c|c|}
\hline & $\begin{array}{c}\text { Reputação } \\
\text { dos } \\
\text { vendedores }\end{array}$ & $\begin{array}{c}\text { Risco } \\
\text { Percebido }\end{array}$ & $\begin{array}{l}\text { Confiança no } \\
\text { intermediário }\end{array}$ & $\begin{array}{c}\text { Confiança } \\
\text { no } \\
\text { vendedor } \\
\text { terceiro }\end{array}$ & $\begin{array}{c}\text { Intenção } \\
\text { de } \\
\text { compra }\end{array}$ \\
\hline $\begin{array}{c}\text { Reputação } \\
\text { dos } \\
\text { vendedores }\end{array}$ & 0,74 & 0,10 & 0,05 & 0,22 & 0,18 \\
\hline $\begin{array}{c}\text { Risco } \\
\text { Percebido }\end{array}$ & 0,10 & 0,50 & 0,12 & 0,13 & 0,36 \\
\hline $\begin{array}{c}\text { Confiança no } \\
\text { intermediário }\end{array}$ & 0,05 & 0,12 & 0,56 & 0,09 & 0,20 \\
\hline
\end{tabular}




\begin{tabular}{|c|c|c|c|c|c|}
\hline $\begin{array}{c}\text { Confiança no } \\
\text { vendedor } \\
\text { terceiro }\end{array}$ & 0,22 & 0,13 & 0,09 & $\mathbf{0 , 6 6}$ & 0,28 \\
\hline $\begin{array}{c}\text { Intenção de } \\
\text { compra }\end{array}$ & 0,18 & 0,36 & 0,20 & 0,28 & $\mathbf{0 , 6 3}$ \\
\hline
\end{tabular}

Fonte: Própria

\subsection{3}

\section{Análise do modelo estrutural}

Após a análise fatorial confirmatória completa, em seguida, foram colocadas em prática as análises dos modelos estruturais da pesquisa. Foram utilizadas as técnicas de modelagem de equações estruturais com o auxílio do software AMOS v21. Por fim, o modelo rival proposto também é avaliado para comparação de resultados.

\subsubsection{1}

\section{Ajuste no modelo proposto}

A tabela 4.3 a seguir é apresentada com o resumo dos dados obtidos com o modelo proposto. A estatística qui-quadrado têm valor significativo $\left(\chi^{2}=359,23\right.$, d.f. $=96, p<0,001, \chi^{2} /$ d.f. $\left.=3,742\right)$, embora ligeiramente acima da orientação de resultados abaixo de 3 (BYRNE, 2010). Segundo Hair et al., (2005), a estatística chi-quadrado é muito sensível ao tamanho de amostra e por isso não deve ser analisada isoladamente. Os índices que avaliam o ajuste incremental deste modelo são um pouco inferiores aos níveis indicados de 0,9 (MALHOTRA, 2010), mas considerados razoáveis entre 0,8 e 0,9 (HAIR et al., 2005): CFI de 0,892; TLI de 0,865; IFI de 0,893. O Parsimony Normed Fit Index (PNFI) para este modelo atende aos valores sugeridos por Hair et al., (2005) (acima de 0,5) com valor de 0,688, enquanto o RMSEA e SRMR ficaram um pouco acima do sugerido de 0,08 com respectivos valores de 0,094 e 0,098. A análise como um todo indica um ajuste do modelo proposto como razoável.

Tabela 3: Índices de Ajuste do Modelo

\begin{tabular}{ccc}
\hline Índice de ajuste & Modelo proposto & $\begin{array}{c}\text { Valor sugerido pela } \\
\text { literatura }\end{array}$ \\
\hline$X^{2} /$ d.f. & 3,742 & $\leq 3,00$
\end{tabular}




$\begin{array}{ccc}\text { CFI } & 0,892 & \geq 0,90 \\ \text { TLI } & 0,865 & \geq 0,90 \\ \text { IFI } & 0,893 & \geq 0,90 \\ \text { PNFI } & 0,688 & \geq 0,50 \\ \text { RMSEA } & 0,094 & \leq 0,08 \\ \text { SRMR } & 0,098 & \leq 0,08\end{array}$

Fonte: Própria

\subsubsection{2}

\section{Teste das hipóteses de pesquisa}

Com os índices obtidos pelo modelo proposto, foram testadas se as hipóteses sugeridas são verificadas estatisticamente. Para tanto, as hipóteses foram analisadas quanto a sua direção, magnitude e significância dos coeficientes estimados (BYRNE, 2010). A tabela 4 e a figura 3 mostram os coeficientes de relação para cada hipótese, bem como o p-valor.

Tabela 4: Coeficientes Padronizados Estimados, Hipóteses e Significâncias para o Modelo Proposto

\begin{tabular}{lccc}
\multicolumn{1}{c}{ Relação Proposta } & $\begin{array}{c}\text { Coeficiente } \\
\text { padronizado }\end{array}$ & p-valor & $\begin{array}{c}\text { Hipótese } \\
\text { verificada }\end{array}$ \\
\hline $\begin{array}{l}\text { (H1) Reputação dos Vendedores } \rightarrow \text { Risco } \\
\text { Percebido }\end{array}$ & $-0,310$ & $<0,001$ & Sim \\
$\begin{array}{l}\text { (H2) Reputação dos Vendedores } \rightarrow \\
\text { Confiança no intermediário }\end{array}$ & 0,207 & 0,038 & Sim \\
$\begin{array}{l}\text { (H3) Reputação dos Vendedores } \rightarrow \\
\text { Confiança nos Vendedores } \\
\text { (H4) Risco Percebido } \rightarrow \text { Confiança nos }\end{array}$ & 0,537 & $<0,001$ & Sim \\
$\begin{array}{l}\text { Vendedores } \\
\text { (H5) Risco Percebido } \rightarrow \text { Confiança nos }\end{array}$ & $-0,215$ & 0,005 & Sim \\
$\begin{array}{l}\text { Intermediários } \\
\text { (H6) Confiança nos Intermediários } \rightarrow\end{array}$ & $-0,338$ & $<0,001$ & Sim \\
$\begin{array}{l}\text { Confiança nos Vendedores } \\
\text { (H7) Confiança nos Intermediários } \rightarrow\end{array}$ & 0,153 & 0,012 & Sim \\
$\begin{array}{l}\text { Intenção de Compra } \\
\text { (H8) Confiança nos Vendedores } \rightarrow\end{array}$ & 0,318 & $<0,001$ & Sim \\
Intenção de Compra & 0,439 & $<0,001$ & Sim \\
\hline
\end{tabular}

Fonte: Própria 


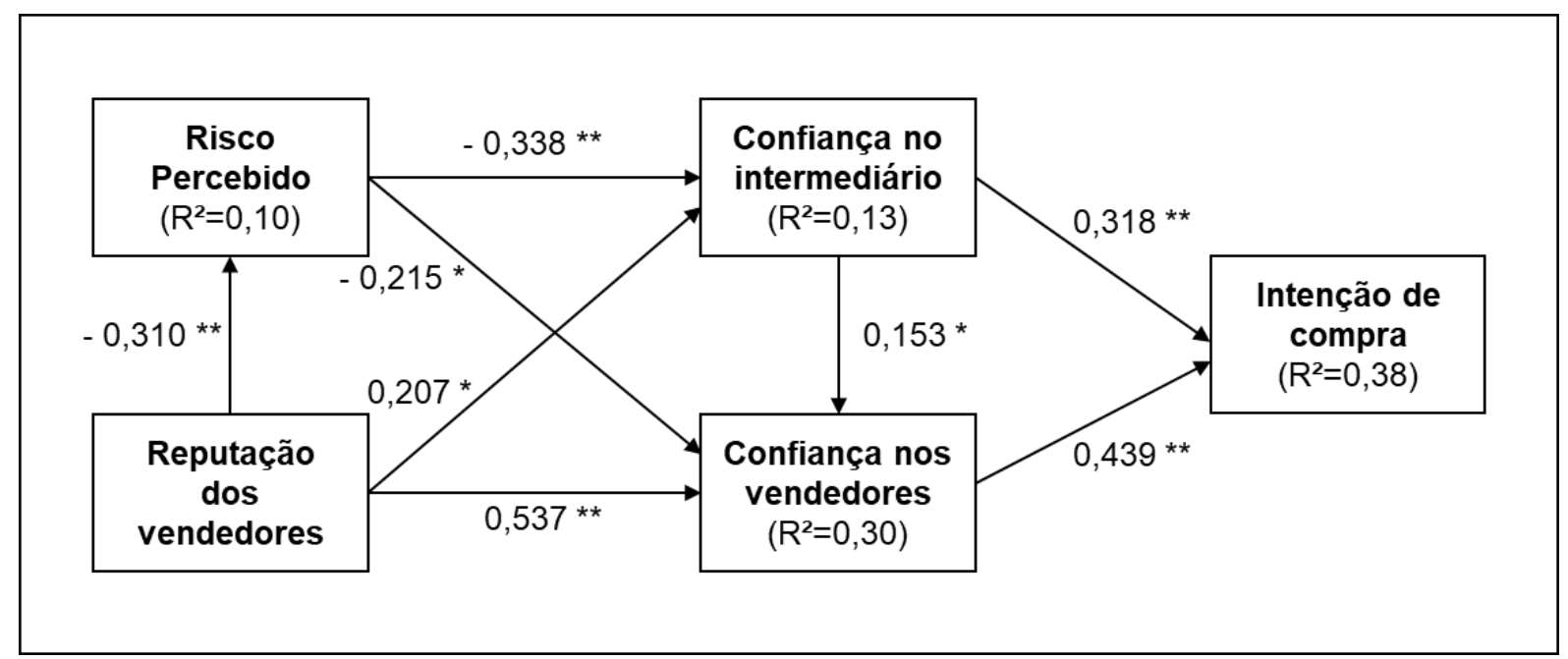

Figura 3: Coeficientes Padronizados Estimados, Hipóteses e Significâncias para o Modelo Proposto

Fonte: Própria

( ${ }^{*}$ indica $\mathrm{p}$-valor $<0,05 ;{ }^{* *}$ indica $\mathrm{p}$-valor $\left.<0,001\right)$

Os resultados aqui obtidos validam todas as hipóteses de pesquisa colocadas, sendo cinco das oito com p-valor abaixo de 0,001. Neste modelo proposto, as relações entre os construtos explicam 38\% da Intenção de Compra de consumidores em marketplaces online. Como a literatura já indicava, as hipóteses que envolveram o construto de Risco Percebido assumiram relações diretas e negativas.

\subsection{4 \\ Análise de modelos rivais}

Avaliações de modelos estruturais se comportam de maneira diferente de modelos de mensuração por permitirem a comparação entre propostas alternativas (HAIR et al., 2005). Conforme colocado no subcapítulo 2.6, muito se discutiu na literatura acadêmica a respeito das prerrogativas da Intenção de Compra em ambientes virtuais. O modelo rival neste estudo coloca o Risco Percebido como principal antecedente da Intenção de Compra dos consumidores em marketplaces online. Os resultados aqui obtidos mostram que de fato, o modelo possui melhores índices de ajuste quando analisados pela ótica do modelo estrutural rival. A estatística índice qui-quadrado teve um valor significativo $\left(\chi^{2}=319,57\right.$, d.f. $=95, \mathrm{p}$ $<0,001, \chi^{2} /$ d.f. $\left.=3,364\right)$, embora também tenha ficado ligeiramente acima da orientação de valores abaixo de 3 (BYRNE, 2010). Os índices de ajuste incremental 
do modelo rival também tiveram resultados superiores ao modelo anterior: CFI de 0,908; TLI de 0,901; IFI de 0,909. O Parsimony Normed Fit Index (PNFI) também atendeu os valores mínimos sugeridos com 0,693, enquanto o RMSEA e SRMR se sobressaíram melhores que o modelo originalmente proposto com respectivos valores de 0,080 e 0,072. O resumo dos índices de ajuste pelo modelo estrutural alternativo obtidos encontra-se na tabela 5 .

Tabela 5: Índices de Ajuste do Modelo

\begin{tabular}{ccc}
\hline Índice de ajuste & Modelo proposto & $\begin{array}{c}\text { Valor sugerido pela } \\
\text { literatura }\end{array}$ \\
\hline$X^{2} /$ d.f. & 3,364 & $\leq 3,00$ \\
CFI & 0,908 & $\geq 0,90$ \\
TLI & 0,901 & $\geq 0,90$ \\
IFI & 0,909 & $\geq 0,90$ \\
PNFI & 0,693 & $\geq 0,50$ \\
RMSEA & 0,080 & $\leq 0,08$ \\
SRMR & 0,072 & $\leq 0,08$
\end{tabular}

Fonte: Própria

Com um ajuste de modelo considerado satisfatório, foram testadas as hipóteses de pesquisa. Da mesma forma como no modelo anterior, todas as hipóteses foram verificadas válidas com grande parte delas com p-valor abaixo de 0,001 .

Tabela 6: Coeficientes Padronizados Estimados, Hipóteses e Significâncias para o Modelo Rival Proposto

\begin{tabular}{lccc}
\multicolumn{1}{c}{ Relação Proposta } & $\begin{array}{c}\text { Coeficiente } \\
\text { padronizado }\end{array}$ & p-valor & $\begin{array}{c}\text { Hipótese } \\
\text { verificada }\end{array}$ \\
\hline $\begin{array}{l}\text { (H1) Reputação dos Vendedores } \rightarrow \text { Risco } \\
\text { Percebido }\end{array}$ & $-0,199$ & 0,012 & Sim \\
$\begin{array}{l}\text { (H2) Reputação dos Vendedores } \rightarrow \\
\begin{array}{l}\text { Confiança no Intermediário } \\
\text { (H3) Reputação dos Vendedores } \rightarrow\end{array}\end{array}$ & 0,226 & $<0,001$ & Sim \\
$\begin{array}{l}\text { Confiança nos Vendedores } \\
\text { (H) }\end{array}$ & 0,424 & $<0,001$ & Sim
\end{tabular}


(H6) Confiança no Intermediário $\rightarrow$ Confiança nos Vendedores

$0,221<0,001 \quad$ Sim

(H9) Confiança no Intermediário $\rightarrow$ Risco

Percebido

$-0,241<0,001 \quad$ Sim

(H10) Confiança nos Vendedores $\rightarrow$

Risco Percebido

$-0,194 \quad 0,014 \quad$ Sim

(H7) Confiança no Intermediário $\rightarrow$

Intenção de Compra

$0,200<0,001 \quad$ Sim

(H8) Confiança nos Vendedores $\rightarrow$

Intenção de Compra

$0,313<0,001 \quad$ Sim

(H11) Risco Percebido $\rightarrow$ Intenção de

Compra

$-0,431<0,001 \quad$ Sim

Fonte: Própria

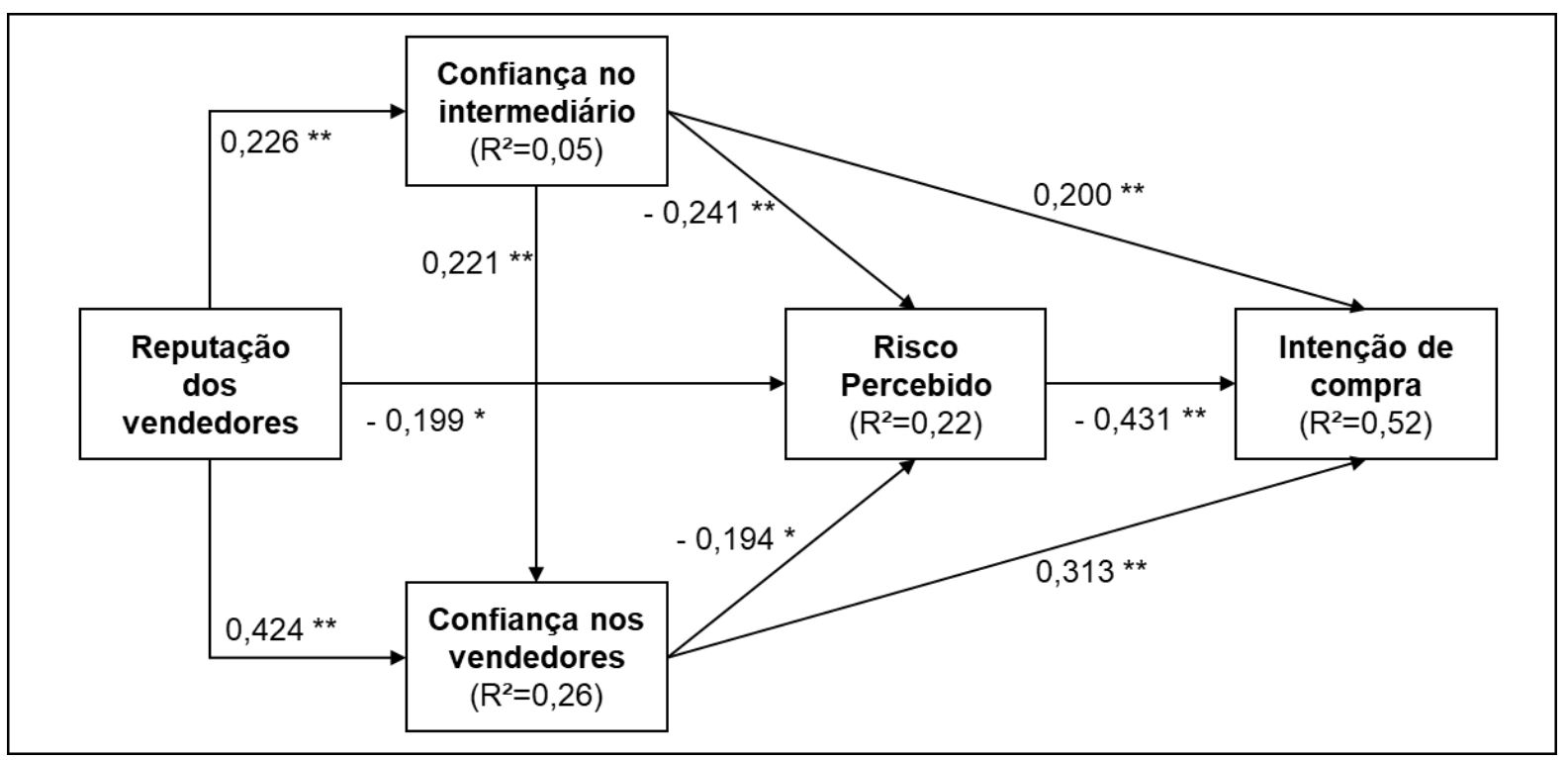

Figura 4: Coeficientes Padronizados Estimados, Hipóteses e Significâncias para o Modelo Rival Proposto

Fonte: Própria

( ${ }^{*}$ indica $p$-valor $<0,05 ;{ }^{* *}$ indica $p$-valor $\left.<0,001\right)$

\section{3}

\section{Discussão dos resultados}

Os resultados permitiram identificar que em ambos os modelos a Reputação dos Vendedores influenciou de maneira direta e positiva os construtos que tratam de aspectos de confiança nas empresas envolvidas na oferta de um produto via marketplace online (H2 e H3). E, por outro lado, a Reputação dos Vendedores afetou de maneira direta e negativa o Risco Percebido pelos consumidores (H1). Estes resultados são condizentes com as prerrogativas sobre a influência da 
reputação sobre consequências comportamentais encontradas anteriormente na literatura (WU et al., 2015; WU; HUANG; FU, 2011; YOO; JEON; HAN, 2016) e compõe o primeiro passo para o cumprimento do objetivo desta pesquisa.

Nos dois modelos estruturais testados, o efeito da Reputação dos Vendedores foi mais forte no estabelecimento da Confiança nos Vendedores (H3) do marketplace online do que sobre o Risco Percebido (H1) ou sobre a Confiança no Intermediário (H2). Em contrapartida da lógica envolvendo essa relação, os resultados da pesquisa promovem que a Reputação dos Vendedores aumenta sua importância no ambiente virtual na medida em que também possui relevância na construção de confiança dos grandes sites intermediadores, uma vez que não houve estudos anteriores na literatura que abordassem essa perspectiva direta.

Essas relações abrem uma série de inferências acerca da construção e manutenção de reputações tanto para intermediários quanto para vendedores. Dentre elas, intermediários devem se policiar e promover boas práticas comerciais em seus marketplaces a fim de que seus vendedores parceiros recebam boas avaliações. Em tese, os custos dessas ações (treinamentos e fiscalização) não poderiam exceder àqueles custos que a empresa teria se estivesse empenhada em ser uma loja que efetuasse vendas diretas. Por outro lado, essa pesquisa reforça a lógica de que avaliações são especialmente importantes para vendedores em marketplaces online, na medida em que impactam fortemente a percepção de confiança dos consumidores acerca do canal de compras via vendedores terceiros.

Analisando em separado o primeiro modelo, o construto de Risco Percebido influenciou de maneira direta e negativa a confiança tanto no Intermediário (H5) quanto nos Vendedores (H4). Esses fatos vão de encontro com pesquisas anteriores (HONG, 2015; KIM; KOO, 2016) que ressaltam o papel do risco percebido como grande vilão da redução de confiança nas compras online. Desde o início dos primeiros sites de e-commerce já se discute o mesmo tipo de relação entre percepção de risco e confiança (PAVLOU, 2003), mas, em poucos estudos, tal relação foi colocada sob a ótica de marketplaces online e com a reputação dos vendedores como antecedente direto (HONG; CHO, 2011; VERHAGEN; MEENTS; TAN, 2006; WU et al., 2015). Desta forma, os riscos percebidos na compra de produtos via marketplace foram constatados com potencial ameaça na percepção de confiança dos consumidores, especialmente quando é observada a confiança sobre intermediários versus vendedores $(-0,338$ p-valor $<0,01$ e $-0,215$ 
p-valor < 0,05). Esses resultados evidenciam como uma má gestão de vendedores pode impactar na operação de marketplace do intermediário.

Além disso, essa pesquisa constatou o estabelecimento de uma influência positiva da Confiança no Intermediário impactando na Confiança nos Vendedores (H6). Os resultados vão de encontro com o conceito proposto por Stewart (2003) e validam a relação encontrada em outros estudos de compras via marketplace online (HONG; CHO, 2011). Esse movimento de transferência de confiança é importante ser mencionado, na medida em que promove a abertura de uma nova relação entre consumidores e empresas, até mesmo fora do ambiente de marketplace em que o consumidor tenha sido atendido originalmente. Nesse sentido, somando esta pesquisa com a literatura que aborda comportamentos em marketplaces, não fica muito claro onde seria a loja na qual o consumidor efetuaria uma possível recompra. Essa discussão pode levar a questionamentos sobre a sustentabilidade deste modelo de compras online, caso o os consumidores estabeleçam um certo tipo de lealdade junto ao vendedor terceiro e sua loja online fora do marketplace original.

No modelo original, tanto a confiança no Intermediário (H7) quanto a Confiança nos Vendedores (H8) possuíram efeitos positivos e diretos na Intenção de Compra. Assim como pesquisas anteriores (HONG, 2015; LU et al., 2016; PAVLOU; GEFEN, 2005), os resultados aqui indicam que a confiança age com forte influência no comportamento de compra dos consumidores. Sendo assim, em um ambiente com tantos fatores de incertezas que envolvem a compra de um produto de desejo do consumidor, a confiança (no vendedor e/ou no intermediário) pode representar um ganho ou motivação para que o usuário não desista de efetuar uma transação em um marketplace online. Da mesma forma, a falta de confiança, ou até mesmo, a desconfiança em uma das partes envolvidas (vendedor ou intermediário) pode impactar na decisão de comprar ou não dos consumidores.

Em contrapartida, no modelo rival a Confiança no Intermediário e a Confiança nos Vendedores impactaram de maneira direta e negativa no Risco Percebido, respectivamente H9 e H10. Nesse sentido, a confiança tem um papel que antecede o risco percebido no processo de compra. Conforme destacado na literatura (KIM; FERRIN; RAO, 2008; PAVLOU, 2003; VERHAGEN; MEENTS; TAN, 2006), esse tipo de relação não só minimiza os riscos percebidos, mas também ajuda a explicar a intenção de compra dos consumidores. A questão acerca do posicionamento da confiança ser anterior ao risco percebido em marketplaces 
online acaba fazendo sentido na medida em que, como observado pelo exemplo desta pesquisa, a compra em si é colocada sob julgamento mais severo a partir dos riscos envolvendo os agentes que cercam o modelo de marketplaces online. Isto é, os consumidores temem sobre as incertezas após estabelecerem a confiança com intermediadores e vendedores.

Por sua vez, o Risco Percebido teve um impacto muito forte na Intenção de Compra quando avaliado o comportamento do consumidor num ambiente de marketplace online (H11). A hipótese foi confirmada e está de acordo com estudos anteriores (KIM; FERRIN; RAO, 2008; PAVLOU, 2003) que avaliaram a relação do risco com a intenção de compra. Nesta pesquisa, o Risco Percebido foi o construto que obteve a relação mais forte do que a confiança (magnitude de $-0,431$ contra magnitude de 0,200 e 0,313 para a confiança no intermediário e no vendedor, respectivamente). Tal constatação pode ser atribuída ao fato de que consumidores em marketplaces potencializam os riscos percebidos (possíveis defeitos em produtos, atraso nas entregas ou insegurança referente ao vazamento de seus dados pessoais) quando analisados em conjunto com a reputação dos vendedores dentro de marketplaces online.

A comparação entre os modelos, deixa claro que os resultados obtidos por meio do modelo rival são superiores tanto nas medidas de ajuste geral do modelo quanto na explicação da variância da Intenção de Compra $\left(\mathrm{R}^{2}=52 \%\right.$ contra $\mathrm{R}^{2}=38 \%$ no modelo inicial). O teste chi-quadrado para diferença de ajuste entre modelos é significativo para o modelo rival $\left(\Delta \chi^{2}=39,66\right.$, p-valor $\left.<0,01\right)$, indicando melhoria concreta comparada ao resultado encontrado pelo modelo inicial.

Desta forma, ao compararmos ambos resultados, podemos supor que: primeiro, os consumidores estabelecem a confiança antes da avaliação de risco, talvez pelo fato do modelo de comercialização direta no e-commerce antever as relações comerciais via marketplaces; segundo, os riscos de compras via marketplaces são mais sentidos do que em transações diretas, assim como fora observado no modelo rival; terceiro, as reputações dos vendedores assumem papel fundamental no processo de avaliação de confiança e riscos. As tabelas 7 e 8 mostram um comparativo entre os resultados gerados pelos dois modelos e as hipóteses de pesquisa, respectivamente. 
Tabela 7: Comparativo de Índices e resultados entre modelos

\begin{tabular}{ccc}
\hline Índices & Modelo proposto & Modelo Rival \\
\hline$\chi^{2}$ & 359,23 & 319,57 \\
$\chi^{2} /$ d.f. & 3,742 & 3,364 \\
CFI & 0,892 & 0,908 \\
TLI & 0,865 & 0,901 \\
IFI & 0,893 & 0,909 \\
PNFI & 0,688 & 0,693 \\
RMSEA & 0,094 & 0,080 \\
SRMR & 0,098 & 0,072 \\
R $^{2}$ IC & 0,38 & 0,52 \\
\hline
\end{tabular}

Fonte: Própria

Tabela 8: Coeficientes padronizados estimados e significâncias para os modelos estruturais proposto e rival

\begin{tabular}{|c|c|c|c|c|}
\hline Hipótese & $\begin{array}{l}\text { Modelo } \\
\text { proposto }\end{array}$ & p-valor & $\begin{array}{l}\text { Modelo } \\
\text { Rival }\end{array}$ & p-valor \\
\hline $\begin{array}{l}\text { (H1) Reputação dos vendedores } \rightarrow \\
\text { Risco Percebido }\end{array}$ & $-0,310$ & $<0,001$ & $-0,199$ & 0,012 \\
\hline $\begin{array}{l}\text { (H2) Reputação dos vendedores } \rightarrow \\
\text { Confiança no Intermediário }\end{array}$ & 0,207 & 0,038 & 0,226 & $<0,001$ \\
\hline $\begin{array}{l}\text { (H3) Reputação dos vendedores } \rightarrow \\
\text { Confiança nos Vendedores }\end{array}$ & 0,537 & $<0,001$ & 0,424 & $<0,001$ \\
\hline $\begin{array}{l}\text { (H4) Risco Percebido } \rightarrow \text { Confiança } \\
\text { nos Vendedores }\end{array}$ & $-0,215$ & 0,005 & n.a. & n.a. \\
\hline $\begin{array}{l}\text { (H5) Reputação dos vendedores } \rightarrow \\
\text { Confiança no Intermediário }\end{array}$ & $-0,338$ & $<0,001$ & n.a. & n.a. \\
\hline $\begin{array}{l}\text { (H6) Confiança no Intermediário } \rightarrow \\
\text { Confiança nos Vendedores }\end{array}$ & 0,153 & 0,012 & 0,221 & $<0,001$ \\
\hline $\begin{array}{l}\text { (H7) Confiança no Intermediário } \rightarrow \\
\text { Intenção de Compra }\end{array}$ & 0,318 & $<0,001$ & 0,200 & $<0,001$ \\
\hline $\begin{array}{l}\text { (H8) Confiança nos Vendedores } \rightarrow \\
\text { Intenção de Compra }\end{array}$ & 0,439 & $<0,001$ & 0,313 & $<0,001$ \\
\hline $\begin{array}{l}\text { (H9) Confiança no Intermediário } \rightarrow \\
\text { Risco Percebido }\end{array}$ & n.a. & n.a. & $-0,241$ & $<0,001$ \\
\hline
\end{tabular}


(H10) Confiança nos Vendedores $\rightarrow$

Risco Percebido

(H11) Risco Percebido $\rightarrow$ Intenção de

Compra

Fonte: Própria n.a. n.a. $\quad-0,194 \quad 0,014$

n.a. n.a. $-0,431<0,001$ 


\section{5 \\ Conclusões}

\section{1}

\section{Considerações finais}

Esta pesquisa teve como objetivo principal investigar a importância relativa das percepções do comprador sobre as reputações dos vendedores terceiros de $e$-marketplaces $B 2 C$, avaliando seus efeitos na relação de risco percebido e confiança das empresas envolvidas no modelo comercial e os consequentes impactos na intenção de compra dos e-consumidores. Inicialmente, foram levadas em consideração as características particulares deste modelo de negócio e como a inserção de agentes terceiros modifica o cenário de e-commerce tradicional com vendas diretas.

A revisão de literatura contou inicialmente com trabalhos que levam em conta o crescimento do chamado social commerce e a importância da interatividade entre empresas e usuários (HUANG; BENYOUCEF, 2013; WIGAND; BENJAMIN; BIRKLAND, 2008). Nesse sentido, a reputação dos vendedores age como um fato chave no processo de decisão dos consumidores (EKMEKCI, 2011).

Antes de avaliar os impacto dos construtos avaliados na intenção de compra, a revisão de literatura abordou aspectos relevantes no processo de compra seguindo a premissa básica de Mitchell (1999), na qual os consumidores são mais motivados a evitar contratempos, e, por isso, tomam decisões com base nos riscos percebidos e na confiança depositada naqueles que ofertam. O risco percebido foi entendido conforme Bauer (1961) define e as incertezas acerca das compras online foram contextualizadas principalmente por meio de trabalhos de Chiu et al., (2014), Gefen e Pavlou (2012), Kim e Ahn (2006) e Wu et al. (2015). Enquanto isso, a confiança foi estabelecida como uma crença global em torno do grupo de vendedores e seu compromisso com as promessas da loja intermediadora (PAVLOU; GEFEN, 2004).

Durante a coleta de dados, mesmo com pré-testes e cuidados com a experiência de navegação em torno da definição dos agentes que operam em marketplaces, foram observados alguns erros e inconsistências nas respostas enviadas que invalidaram ao todo 102 questionários, representando $24,8 \%$ do total de respostas completas (411). O próprio fato da pesquisa ter encontrado um número significativo de erros, indica que esse tipo de comércio ainda não é completamente compreendido pelos usuários em geral, visto que não fora encontrada nenhuma evidência na amostra que indicasse incapacidade de compreensão $(94,2 \%$ da amostra indicaram que possuem graduação ou pós-graduação em curso ou completados). 
O modelo originalmente proposto teve como objetivo principal reunir os aspectos de Reputação dos Vendedores, Confiança no Intermediário, Confiança nos Vendedores, Risco Percebido e Intenção de Compra. Os resultados da modelagem de equações estruturais realizada validaram todas as hipóteses de pesquisa, confirmando a influência das reputações dos vendedores terceiros e suas respectivas consequências no que cerca o risco percebido, confiança e intenção de compra. Conforme verificado, o Risco Percebido exerceu uma influência maior na confiança no Intermediário do que na confiança em relação aos Vendedores, demonstrando a importância de uma boa gestão dos Intermediários quanto àquele grupo de vendedores que fazem parte do marketplace online.

Contudo, o modelo originalmente proposto foi comparado com um modelo rival, devido ao fato de haver na literatura (KIM; KOO, 2016; PAVLOU, 2003; VERHAGEN; MEENTS; TAN, 2006) certa discussão em torno do principal antecedente da intenção de compra quando analisados risco percebido e confiança. Os resultados encontrados por meio do modelo rival foram superiores tanto em relação aos índices de ajuste geral do modelo quanto em relação a explicação do modelo por meio da variância da Intenção de Compra (52\%). Assim como no modelo original, todas as hipóteses de pesquisa foram verificadas. Em primeiro lugar, a Reputação dos Vendedores exerceu um papel mais forte na Confiança nos Vendedores do que em relação ao Intermediário e no Risco Percebido, ratificando a importância direta entre reputações e confiança.

Em segundo lugar, observamos o fenômeno de transferência de confiança, como proposto por Stewart (2003). Ao verificarmos que a Confiança no Intermediário exerce influência sobre a Confiança nos Vendedores, podemos assumir que os consumidores incorporam os valores e crenças que colocaram na loja intermediária e assumiram que as promessas feitas no marketplace online serão mantidas pelos vendedores terceiros. Contudo, cabe ressaltar que essa relação abre uma possibilidade de discussão acerca da lealdade do consumidor dentro do marketplace original, ou, se uma possível recompra aconteceria em algum dos sites dos próprios vendedores terceiros.

Em terceiro lugar, no contexto do modelo rival desta pesquisa, a Confiança no Intermediário e nos Vendedores terceiros antecederam o Risco Percebido de maneira significativa com efeitos diretos e negativos. Isso é, a confiança depositada nos agentes que ofertam em um determinado marketplace online (intermediário e vendedor) agem de maneira inversamente no Risco Percebido pelos consumidores. A lógica funciona na medida em que ocorrendo falta de confiança, um aumento do risco é manifestado e vice-versa. 
Em quarto lugar, esta pesquisa analisou os principais construtos que afetam diretamente a Intenção de Compra dos consumidores. Dentre eles, o Risco Percebido exerceu o papel mais impactante $(-0,431)$, evidenciando justamente a aversão às possíveis consequências que envolvem as incertezas dentro de um processo de compra em um marketplace online. Por fim, a Confiança nos Vendedores superou a Confiança nos Intermediários na influência sobre a Intenção de Compra. Essa constatação indica exatamente a grande importância das Reputações dos Vendedores e suas consequências indiretas nas Intenções de Compra, uma vez que possui forte relação na Confiança nos Vendedores.

\section{2 \\ Implicações gerenciais}

Os resultados obtidos nesta pesquisa proporcionam algumas sugestões de grande importância para empresas, seja para aquelas que atuam em marketplaces, ou, no setor de ecommerce em geral, ou, para as que atuem num marketplace concorrente, ou tenham planos de integrar uma operação em marketplace online, tanto como loja intermediadora ou como loja vendedora.

Dentre algumas das recomendações direcionadas às lojas intermediadoras de marketplaces online estão, em primeiro lugar, o refinamento e aprimoramento na gestão de vendedores e sistema de reputações. Além de promover a transparência e interatividade, as empresas devem saber o momento certo de recrutar e desvincular vendedores em detrimento das reputações obtidas. Em segundo lugar, fica evidenciada a necessidade do constante investimento em marca e atendimento de clientes visando manter a confiabilidade na empresa. Em terceiro lugar, o treinamento e a comunicação junto aos vendedores terceiros deve ser colocada como atividade prioritária a fim de cultivar uma base saudável e competente de vendedores, e, possivelmente, que opere exclusivamente na sua operação de marketplace online. Em quarto lugar, o modelo de pesquisa desenvolvido aqui se apresenta como um método válido de avaliação benchmark para marketplaces online e seus sistemas de reputação de vendedores. Uma vez que o produto final do modelo apresentado reflete em indicadores de performance, empresas interessadas em avaliar o reflexo de seus sistemas de reputação e vendedores podem extrair informações de grande valor de seus clientes ao adotarem os métodos de pesquisa aqui empregados. Por fim, em quinto lugar, a transferência de confiança para vendedores terceiros acende uma questão a respeito da recompra dos consumidores e onde ela 
seria feita. Cabe aqui, como recomendação, uma investigação sobre os efeitos desta constatação com o intuito de manter a sustentabilidade de seus negócios.

Por outro lado, esta pesquisa ainda promove algumas recomendações para vendedores terceiros que operam em marketplaces online. Primeiramente, a manutenção de uma pontuação elevada em sistemas de reputação é primordial para sucesso neste tipo de comercialização. Como constatado, uma boa reputação facilita a tomada de decisão de compra dos consumidores. Em segundo lugar, esta pesquisa evidencia que o vínculo entre intermediadores e vendedores é mais próximo do que se imaginava. Sendo assim, vendedores devem buscar estabelecer parcerias em conjunto com intermediadores confiáveis, podendo ser punidos com perda de mercado ao se vincular com lojas intermediárias que não promovem uma operação de marketplace corretamente.

\section{3 \\ Limitações da pesquisa}

Assim como em outros estudos, esta pesquisa apresenta algumas limitações em virtude dos métodos escolhidos para amostragem e também decorrente da coleta de dados juntamente com o instrumento de pesquisa. Em relação aos critérios adotados para amostragem, os métodos adotados para coleta de dados por conveniência e "bola de neve" utilizados neste estudo, não permitem a generalização dos resultados, visto que o perfil da amostra não se mostrou compatível com o perfil da população alvo deste estudo.

O nível de proximidade dos respondentes com o objeto de pesquisa também não pode ser desconsiderado, visto que também foram abordadas pessoas que trabalhassem ou possuíssem uma loja virtual. Desta forma, a pesquisa não pôde filtrar opiniões formadas a respeito do modelo de marketplace online em geral. Os resultados encontrados podem ter sido amenizados ou potencializados por esses indivíduos com opiniões fortemente enviesadas.

Da mesma forma, apesar do cuidado e planejamento do instrumento de pesquisa, a aplicação de um questionário online implica algumas limitações. Um bom exemplo pode ser observado pelo número significativo de respondentes que não souberam indicar corretamente o papel dos agentes no exemplo de marketplace online exibido no instrumento de pesquisa. Isso é, a coleta de dados via plataforma virtual não garantiu que os respondentes despendessem atenção e dedicação necessários para a melhor obtenção de dados possível.

O mesmo pode se afirmar sobre a opção de utilização de um exemplo de uma loja real que opera em marketplace, a Americanas.com. Este fato, não permite que os resultados deste 
estudo sejam garantidos para todo e qualquer ambiente de marketplace online. A escolha de uma loja em específico foi justificada para promover uma experiência idêntica a todos respondentes, porém, traz consigo restrições em relação à generalização frente às inúmeras opções de experiências em marketplaces que existem no mercado.

\section{4 \\ Sugestões de pesquisas futuras}

Em virtude da limitação de escopo deste projeto, foram analisados somente os impactos das principais barreiras no processo de compra dos consumidores. Certamente, muitos outros fatores que interferem na Intenção de Compra são dignos de investigação em ambientes de marketplaces online. Desta mesma forma, o uso do modelo apresentado nesta pesquisa pode ser expandido com o intuito de agregar outros obstáculos que possam bloquear comportamentos de compra, além de outros construtos que signifiquem fortes motivadores para consumidores.

Durante a revisão de literatura e a análise de dados, um dos construtos se mostrou merecedor de aprimoramentos para estudos mais complexos e assertivos em compras online. Os sistemas de Reputação dos Vendedores encontrados em plataformas virtuais se diferenciam muito entre si e mudam constantemente conforme o passar do tempo. Neste caso, é válida uma investigação mais profunda acerca dos significados interpretados pelos consumidores para a determinação do que é uma boa ou baixa reputação para uma loja ou vendedor.

Por fim, como já mencionado no item 4.3, algumas constatações feitas nesta pesquisa levam a questões em torno de como se comportam consumidores em cenários de recompras quando confrontados ambientes de marketplaces e ambientes virtuais próprios de pequenos vendedores terceiros dos mesmos marketplaces. Esse tipo de investigação poderia responder sobre quais plataformas se mostram mais sustentáveis ao longo do tempo, aquelas que terceirizam o serviço ou as lojas que abraçam todo o processo de comercialização e atuam de maneira mais próxima e direta. 
6

\section{Referências bibliográficas}

B2W. Relatório 4T2016. Rio de Janeiro: [s.n.].

BA, S.; PAVLOU, P. A. Evidence of the Effect of Trust Building Technology in Electronic Markets: Price Premiums and Buyer Behavior. MIS Quarterly, v. 26, n. 3, p. 243-268, 2002.

BAUER, R. A. Risk Handling in Drug Adoption: The Role of Company Preference. The Public Opinion Quarterly, v. 25, n. 4, p. 546-559, 1961.

BLACK, K. Business Statistics For Contemporary Decision Making. 6th. ed. [s.1.] John Wiley \& Sons, 2011.

BOLTON, G.; GREINER, B.; OCKENFELS, A. Engineering Trust: Reciprocity in the Production of Reputation Information. Management Science, v. 59, n. 2, p. 265-285, 2013. BYRNE, B. M. Structural Equation Modeling with AMOS. 2nd. ed. [s.1.] Routledge, 2010. CABRAL, L.; HORTAÇSU, A. The Dynamics of Seller Reputation: Evidence from eBAY. The Journal of Industrial Economics, v. 58, n. 1, p. 54-78, mar. 2010.

CAI, H. et al. Seller reputation: From word-of-mouth to centralized feedback. International Journal of Industrial Organization, v. 34, n. 1, p. 51-65, 2014.

CHANG, H. H.; CHEN, S. W. The impact of online store environment cues on purchase intention. Online Information Review, v. 32, n. 6, p. 818-841, 2008.

CHIU, C. M. et al. Understanding customers' repeat purchase intentions in B2C e-commerce: The roles of utilitarian value, hedonic value and perceived risk. Information Systems Journal, v. 24 , n. 1 , p. $85-114,2014$.

COCOSILA, M.; TRABELSI, H. An integrated value-risk investigation of contactless mobile payments adoption. Electronic Commerce Research and Applications, v. 20, p. 159-170, 2016.

COLUCCI, S. et al. A semantic-based fully visual application for matchmaking and query refinement in B2C e-marketplaces. Proceedings of the 8th international conference on Electronic commerce The new e-commerce: innovations for conquering current barriers, obstacles and limitations to conducting successful business on the internet - ICEC '06, p. $174,2006$.

E-COMMERCEBRASIL. Walmart brasileiro vai trabalhar apenas com marketplace na internet. Disponível em: <https://www.ecommercebrasil.com.br/noticias/walmart-anunciamarketplace-brasil/>. Acesso em: 5 dez. 2017a.

E-COMMERCEBRASIL. Estudo mostra Raio X das reclamações online dos consumidores.

Disponível em: <https://www.ecommercebrasil.com.br/noticias/estudo-mostra-raio-X-das- 
reclamacoes-online-dos-consumidores/>. Acesso em: 17 nov. $2017 \mathrm{~b}$.

EKMEKCI, M. Sustainable reputations with rating systems. Journal of Economic Theory, v. 146, n. 2, p. 479-503, 2011.

FAN, Y.; JU, J.; XIAO, M. Reputation premium and reputation management: Evidence from the largest e-commerce platform in China. International Journal of Industrial Organization, v. 46, p. 63-76, 2016.

FANG, Y. et al. Trust, Satisfaction, and online repurchase intention: The moderating role of perceived effectiveness of e-Commerce institutional mechanisms. MIS Quarterly, v. 38, n. 2, p. 407-427, 2014.

FLANAGIN, A. J. et al. Mitigating risk in ecommerce transactions: Perceptions of information credibility and the role of user-generated ratings in product quality and purchase intention. Electronic Commerce Research, v. 14, n. 1, p. 1-23, 2014.

FORNELL, C.; LARCKER, D. F. Evaluating Structural Equation Models with Unobservable Variables and Measurement Error. Journal of Marketing Research, v. 18, n. 1, p. 39, 1981.

GEFEN, D. E-commerce: the role of familiarity and trust. Omega, v. 28, n. 6, p. 725-737, 2000 .

GEFEN, D.; CARMEL, E. Why the First Provider Takes it All: The Consequences of a Low Trust Culture on Pricing and Ratings in Online Sourcing Markets. European Journal of Information Systems, v. 22, n. 6, p. 604-618, 2013.

GEFEN, D.; PAVLOU, P. A. The Boundaries of Trust and Risk: The Quadratic Moderating Role of Institutional Structures. Information Systems Research, v. 23, n. April 2014, p. 940 959, 2012.

HAIR, J. et al. Análise multivariada de dados. $5^{\text {a }}$ ed. Porto Alegre: Pearson Education, Inc., 2005.

HONG, I. B. Understanding the consumer's online merchant selection process: The roles of product involvement, perceived risk, and trust expectation. International Journal of Information Management, v. 35, n. 3, p. 322-336, 2015.

HONG, I. B.; CHO, H. The impact of consumer trust on attitudinal loyalty and purchase intentions in B2C e-marketplaces: Intermediary trust vs. seller trust. International Journal of Information Management, v. 31, n. 5, p. 469-479, 2011.

HUANG, Z.; BENYOUCEF, M. From e-commerce to social commerce: A close look at design features. Electronic Commerce Research and Applications, v. 12, n. 4, p. 246-259, 2013. HWANG, Y.; KIM, D. J. Customer self-service systems: The effects of perceived Web quality with service contents on enjoyment, anxiety, and e-trust. Decision Support Systems, v. 43, n. 
3, p. 746-760, 2007.

JACOBY, J.; KAPLAN, L. B. The Components of Perceived Risk. Advances in Consumer Research, v. 3, p. 382-393, 1972.

JARVENPAA, S. L.; TRACTINSKY, N.; SAARINEN, L. Consumer Trust in an Internet Store: A Cross-Cultural Validation. Journal of Computer-Mediated Communication, v. 5, n. 2, p. 27, 1999.

JOLIVET, G.; JULLIEN, B.; POSTEL-VINAY, F. Reputation and prices on the e-market: Evidence from a major French platform. International Journal of Industrial Organization, v. 45 , p. $59-75,2015$.

KIM, C. et al. Factors influencing Internet shopping value and customer repurchase intention. Electronic Commerce Research and Applications, v. 11, n. 4, p. 374-387, 2012.

KIM, D. J.; FERRIN, D. L.; RAO, H. R. A trust-based consumer decision-making model in electronic commerce: The role of trust, perceived risk, and their antecedents. Decision Support Systems, v. 44, n. 2, p. 544-564, 2008.

KIM, G.; KOO, H. The causal relationship between risk and trust in the online marketplace: A bidirectional perspective. Computers in Human Behavior, v. 55, p. 1020-1029, 2016.

KIM, M.-S.; AHN, J. H. Comparison of trust sources of an online market-maker in the emarketplace: Buyer's and seller's perspectives. Journal of Computer Information Systems, v. 47, n. 1, p. 84, 2006.

KIM, Y.; PETERSON, R. A. A Meta-analysis of Online Trust Relationships in E-commerce. Journal of Interactive Marketing, v. 38, p. 44-54, 2017.

LU, B. et al. Trust antecedents, trust and online microsourcing adoption: An empirical study from the resource perspective. Decision Support Systems, v. 85, p. 104-114, 2016.

LU, B.; FAN, W.; ZHOU, M. Social presence, trust, and social commerce purchase intention: An empirical research. Computers in Human Behavior, v. 56, p. 225-237, 2016.

MALHOTRA, N. K. Marketing Research - An Applied Orientation. 6th. ed. New Jersey: Prentice Hall, 2010.

MAYER, R. C.; DAVIS, J. H.; SCHOORMAN, F. D. An Integrative Model of Organizational Trust. Academy of Management Review, v. 20, n. 3, p. 709-734, 1 jul. 1995.

MCKNIGHT, D. H.; CUMMINGS, L. L.; CHERVANY, N. L. Initial trust formation in new organizational relationships. Academy of Management Review, v. 23, n. 3, p. 473-490, 1998. MITCHELL, V. W. Consumer perceived risk: conceptualisations and models. European Journal of Marketing, v. 33, n. 1/2, p. 167-195, 1999.

OLIVEIRA, T. et al. Modelling and testing consumer trust dimensions in e-commerce. 
Computers in Human Behavior, v. 71, p. 153-164, 2017.

PAVLOU, P. A. Consumer Acceptance of Electronic Commerce : Integrating Trust and Risk with the Technology Acceptance Model. International Journal of Electronic Commerce, v. 4415, n. January, p. 69-103, 2003.

PAVLOU, P. A.; GEFEN, D. Building Effective Online Marketplaces with Institution-Based Trust. Information Systems Research, v. 15, n. 1, p. 37-59, mar. 2004.

PAVLOU, P. A.; GEFEN, D. Psychological contract violation in online marketplaces: Antecedents, consequences, and moderating role. Information Systems Research, v. 16, n. 4, p. 372-399, 2005.

PETER, J. P.; RYAN, M. J. Investigation of Brand Risk the Level. Journal of Marketing Research, v. 13, n. 2, p. 184-188, 1976.

PROCON-SP. RANKING FUNDAMENTADAS. São Paulo: [s.n.].

RIQUELME, I. P.; ROMÁN, S.; IACOBUCCI, D. Consumers' Perceptions of Online and Offline Retailer Deception: A Moderated Mediation Analysis. Journal of Interactive Marketing, v. 35, p. 16-26, 2016.

SHAN, Y. How credible are online product reviews? the effects of self-generated and systemgenerated cues on source credibility evaluation. Computers in Human Behavior, v. 55, p. 633-641, 2016.

SHAPIRO, C. Consumer Information, Product Quality, and Seller Reputation. The Bell Journal of Economics, v. 13, n. 1, p. 20, 1982.

SPERBER, A. D. Translation and validation of study instruments for cross-cultural research. Gastroenterology, v. 126, n. 1, p. S124-S128, 2004.

STEWART, K. J. Trust Transfer on the World Wide Web. Organization Science, v. 14, n. 1, p. 5-17, 2003.

VERHAGEN, T.; MEENTS, S.; TAN, Y.-H. Perceived risk and trust associated with purchasing at electronic marketplaces. European Journal of Information Systems, v. 15, n. 6, p. 542-555, 2006.

WALSH, G. et al. Relationship between Online Retailers' Reputation and Product Returns. British Journal of Management, v. 27, n. 1, p. 3-20, 2016.

WANG, Q. et al. Seller reputation or product presentation? An empirical investigation from cue utilization perspective. International Journal of Information Management, v. 36, n. 3, p. 271-283, 2016.

WEBSHOPPERS. $\quad \mathbf{3 5}^{\mathbf{0}}$ relátorio. São Paulo: [s.n.]. Disponível em: <https://www.ebit.com.br/webshoppers>. 
WIGAND, R. T.; BENJAMIN, R. I.; BIRKLAND, J. L. H. Web 2.0 and Beyond: Implications for Electronic Commerce. 10th international conference on Electronic commerce - ICEC '08, p. 1, 2008.

WILLIAMSON, O. E. Transaction-Cost Economics: The Governance of Contractual Relations. The Journal of Law and Economics, v. 22, n. 2, p. 233-261, 1979.

WU, K. et al. How do you feel when you see a list of prices? The interplay among price dispersion, perceived risk and initial trust in Chinese $\mathrm{C} 2 \mathrm{C}$ market. Journal of Retailing and Consumer Services, v. 25, p. 36-46, 2015.

WU, K. et al. Complexity or simplicity? Designing product pictures for advertising in online marketplaces. Journal of Retailing and Consumer Services, v. 28, p. 17-27, 2016.

WU, W. Y.; HUANG, P. C.; FU, C. S. The influence of an online auction's product price and e-retailer reputation on consumers' perception, attitude, and behavioral intention. Scandinavian Journal of Psychology, v. 52, n. 3, p. 290-302, 2011.

YAN, Q. et al. E-WOM from e-commerce websites and social media: Which will consumers adopt? Electronic Commerce Research and Applications, v. 17, p. 62-73, 2016.

YOO, B.; JEON, S.; HAN, T. An analysis of popularity information effects: Field experiments in an online marketplace. Electronic Commerce Research and Applications, v. 17, p. 87-98, 2016.

ZHANG, T. et al. Welfare economics of review information: Implications for the online selling platform owner. International Journal of Production Economics, v. 184, n. October 2016, p. 69-79, 2017.

ZHOU, L.; ZHANG, P.; ZIMMERMANN, H. D. Social commerce research: An integrated view. Electronic Commerce Research and Applications, v. 12, n. 2, p. 61-68, 2013. 


\section{Apêndice}

Apêndice 1

POR FAVOR, RESPONDA A TODAS AS PERGUNTAS DESTE QUESTIONÁRIO COM ATENÇÃO. AGRADECEMOS DESDE JÁ SUA COLABORAÇÃO.

1. Primeira etapa: Dados sócio demográficos.

Idade

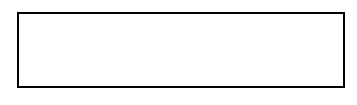

Sexo

Masculino

Feminino

Você estima que sua renda familiar média esteja em que faixa de valores:
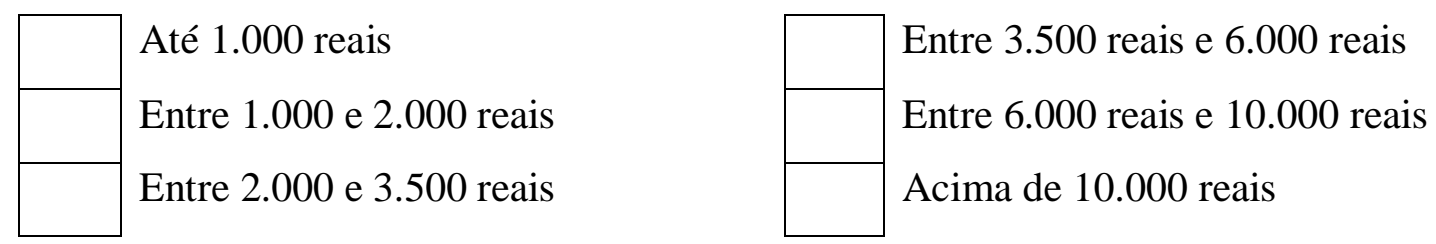

\begin{tabular}{l|l|l|l|l}
\hline Escolaridade & $\begin{array}{l}\text { Ensino fundamental incompleto } \\
\text { Ensino fundamental completo } \\
\text { Ensino médio incompleto }\end{array}$ \\
\cline { 2 - 2 } & $\begin{array}{l}\text { Ensino médio completo } \\
\text { Graduação incompleto } \\
\text { Graduação completo } \\
\text { Pós-graduação incompleto } \\
\text { Pós-graduação completo }\end{array}$ \\
\cline { 2 - 2 }
\end{tabular}

Número de sites/lojas online que você realizou compras nos últimos 12 meses:

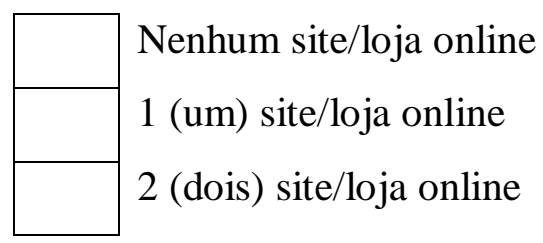




\begin{tabular}{|l|l}
3 (três) site/loja online \\
4 (quatro) ou mais sites/lojas online
\end{tabular}

Você sabe o que é um marketplace?

Sim

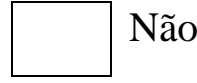

Você efetuou alguma compra em um marketplace?
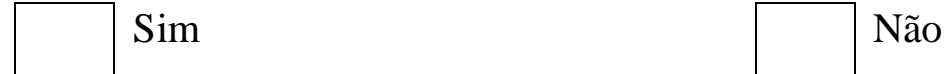

Qual marketplace você efetuou compra? (apenas quem respondeu "Sim" na questão anterior) 
2. Segunda etapa: Nesta etapa, antes do questionário final, abordaremos alguns conceitos particulares sobre vendas online:

a. Marketplace - um tipo de venda online que une compradores, intermediários e vendedores terceiros;

b. Intermediários - grandes lojas online que fazem ofertas de produtos que outras empresas vendem;

c. Vendedores terceiros - empresas que executam os serviços atrelados a venda de produtos no marketplace.

A imagem abaixo fornece um exemplo de uma oferta de celular em uma grande loja de varejo online. É possível identificar 1 (uma) marca de uma loja intermediadora e outros 5 (cinco) logos de vendedores terceiros que atuam neste site por meio de marketplace online (quando um vendedor terceiro vende em uma loja intermediadora). Marque nas opções abaixo (1) uma marca/nome correspondente aos conceitos abordados anteriormente:

\section{Loja intermediária}

Vendedor terceiro
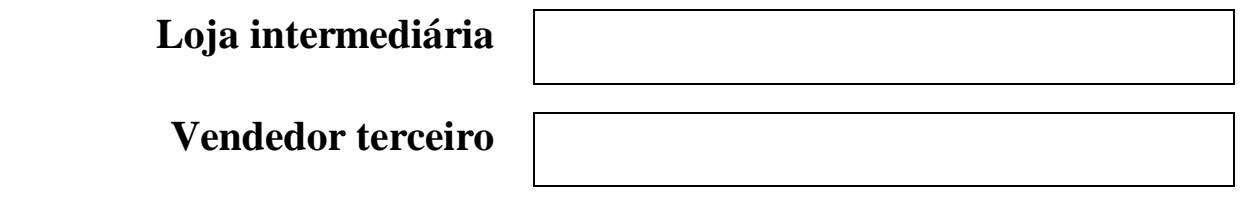

\section{AMERICANAS.com}

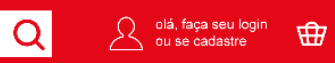

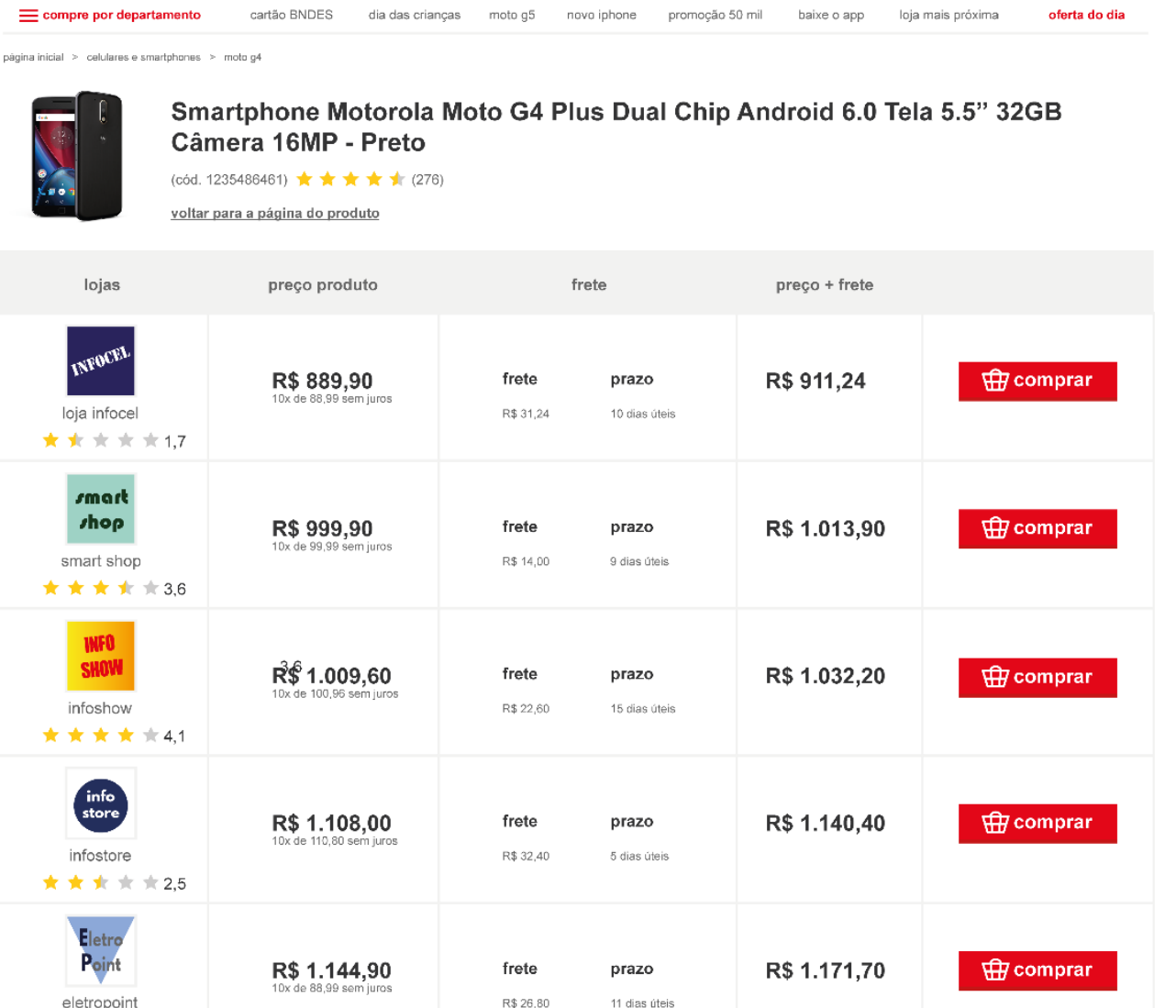




\section{Terceira Etapa: Questionário}

Com base nas suas percepções sobre o funcionamento e estrutura dos marketplaces online da Americanas.com, indique qual o seu grau de concordância ou discordância com cada uma das afirmativas abaixo:

$\begin{array}{ccccc}\text { Discordo } & \text { Discordo } & \begin{array}{c}\text { Nem } \\ \text { concordo, } \\ \text { totalmente }\end{array} & \begin{array}{c}\text { Concordo } \\ \text { em parte } \\ \text { discordo }\end{array} & \begin{array}{c}\text { Concordo } \\ \text { totalmente }\end{array}\end{array}$

1. Esses vendedores terceiros são bem conhecidos.

\begin{tabular}{|l|l|l|l|l|}
\hline 1 & 2 & 3 & 4 & 5 \\
\hline
\end{tabular}

2. Esses vendedores terceiros tem uma reputação ruim no mercado.

\begin{tabular}{|l|l|l|l|l|}
\hline 1 & 2 & 3 & 4 & 5 \\
\hline
\end{tabular}

3. Esses vendedores terceiros tem uma boa reputação.

\begin{tabular}{l}
\begin{tabular}{|l|l|l|l|l|}
\hline 1 & 2 & 3 & 4 & 5 \\
\hline 1 & 2 & 3 & 4 & 5 \\
\hline
\end{tabular} \\
\hline
\end{tabular}
possa comprar neste marketplace não atenda aos requisitos de desempenho originalmente previstos pela compra.

5. É provável que fazer compras neste marketplace fará com que eu perca o controle sobre a privacidade das minhas informações pessoais.

6. É provável que fazer compras neste marketplace fará com que eu perca o controle sobre as informações de métodos de pagamento.

7. É provável que a compra neste marketplace fará com que eu sofra uma perda financeira devido aos custos ocultos, custos de manutenção ou prejuízos por falta de garantia em caso de falhas.

8. É provável que o vendedor terceiro deste marketplace online possa deixar de entregar o produto ou efetuar uma entrega além do prazo.

9. Mesmo que não fossem monitorados, eu confiaria que a loja

\begin{tabular}{|l|l|l|l|c|}
\hline 1 & 2 & 3 & 4 & 5 \\
\hline \multicolumn{1}{|l|}{} \\
\hline 1 & 2 & 3 & 4 & 5 \\
\hline
\end{tabular}

\begin{tabular}{|l|l|l|l|l|}
\hline 1 & 2 & 3 & 4 & 5 \\
\hline
\end{tabular}
intermediária faria o trabalho direito.

\begin{tabular}{|l|l|l|l|l|}
\hline 1 & 2 & 3 & 4 & 5 \\
\hline
\end{tabular}

\begin{tabular}{|l|l|l|l|l|}
\hline 1 & 2 & 3 & 4 & 5 \\
\hline
\end{tabular}




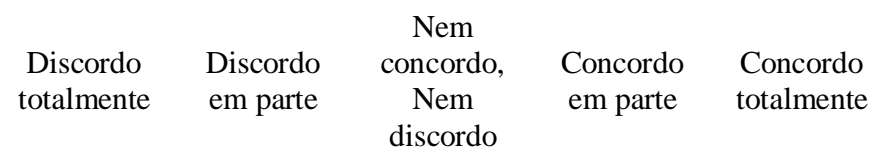

10. Eu confio na loja intermediária.

\begin{tabular}{|l|l|l|l|l|}
\hline 1 & 2 & 3 & 4 & 5 \\
\hline
\end{tabular}

11. Eu acredito que a loja

intermediária é confiável.

\begin{tabular}{|l|l|l|l|l|}
\hline 1 & 2 & 3 & 4 & 5 \\
\hline
\end{tabular}

12. Mesmo se não fossem monitorados, eu confiaria que os

\begin{tabular}{|l|l|l|l|l|}
\hline 1 & 2 & 3 & 4 & 5 \\
\hline
\end{tabular}
vendedores terceiros deste marketplace fariam o trabalho direito.

13. Eu confio nos vendedores terceiros deste marketplace.

\begin{tabular}{|l|l|l|l|l|}
\hline 1 & 2 & 3 & 4 & 5 \\
\hline
\end{tabular}

14. Eu acredito que os vendedores terceiros são confiáveis.

\begin{tabular}{|l|l|l|l|l|}
\hline 1 & 2 & 3 & 4 & 5 \\
\hline
\end{tabular}

15. Eu me sentiria confortável em comprar produtos neste marketplace.

\begin{tabular}{|l|l|l|l|l|}
\hline 1 & 2 & 3 & 4 & 5 \\
\hline
\end{tabular}

16. Eu me sentiria confortável a procurar informações de produtos

\begin{tabular}{|l|l|l|l|l|}
\hline 1 & 2 & 3 & 4 & 5 \\
\hline
\end{tabular}
neste marketplace.

17. Eu me sentiria confortável em receber informações gratuitas de

\begin{tabular}{|l|l|l|l|l|}
\hline 1 & 2 & 3 & 4 & 5 \\
\hline
\end{tabular}
produtos deste marketplace.

18. Eu me sentiria confortável fornecendo minhas informações pessoais a este marketplace a fim de receber um serviço personalizado.

19. Eu me sentiria confortável em desenvolver um relacionamento com

\begin{tabular}{|l|l|l|l|l|}
\hline 1 & 2 & 3 & 4 & 5 \\
\hline
\end{tabular}
este marketplace.

\begin{tabular}{|l|l|l|l|l|}
\hline 1 & 2 & 3 & 4 & 5 \\
\hline
\end{tabular}

Muito obrigado por sua participação! Você conhece pessoas que compram online regularmente? Compartilhe o link deste questionário! 